\title{
On Chinese appositive relative clauses
}

\author{
Francesca Del Gobbo
}

Recived: 31 January 2009 / Accepted 23 July 2010 / Published online: 28 December 2010

The Author(s) 2010. This article is published with open access at Springerlink.com

\begin{abstract}
There is currently no consensus in the literature with the respect to the semantic status of relative clauses in Mandarin Chinese. Some authors (Zhang 2001; Del Gobbo 2003, 2004, 2005) claim that relative clauses in Mandarin Chinese can only be interpreted as restrictives; others (see Lin 2003) instead maintain that relative clauses in this language can be both restrictive and appositive. In this paper, I claim that Chinese relative clauses modifying proper names and pronouns can indeed be appositive, but they are still crucially different from appositive relative clauses in English. Following Cinque's (2006a, 2008a) distinction between "integrated appositive relative clauses" and "non-integrated" ones, I claim that Chinese appositive relatives belong to the class of the "integrated" ones. I furthermore propose that the typological difference between the "integrated" appositives and the "non-integrated" ones is due to the absence versus presence of the relative pronoun. Adopting Cinque's (2006a, 2008a) theory of relativization, I propose a structure for Chinese relative clauses whereby c-command of the internal head of the relative is disallowed. This explains why the internal head of the Chinese relative clause can never be generated as a relative pronoun and, more generally, why overt relative pronouns are unavailable in prenominal relative clauses cross-linguistically. Last, the theory here outlined makes the strong empirical prediction that no prenominal relative clause can be appositive in the canonical sense.
\end{abstract}

F. Del Gobbo $(\bowtie)$

Department of Linguistics, School of Social Sciences, University of California, Irvine, 3151 Social Science Plaza, Irvine, CA 92697-5100, USA

e-mail: fdelgobb@uci.edu 
Keywords Restrictive relative clauses - Appositive relative clauses · Prenominal relative clauses · Mandarin Chinese

\section{Introduction}

In this paper I tackle the issue of the interpretation and structure of a specific type of relative clause in Chinese and, more precisely, of relative clauses that would in principle qualify as appositives by virtue of the fact that they modify proper names and pronouns. Del Gobbo (2001, 2002, 2003) and Zhang (2001) maintain that Chinese relative clauses consistently show the behavior of restrictive relative clauses, contra Lin (2003) who instead claims that appositive relative clauses are possible in Chinese, specifically when they modify proper names. Inspired by Lin's (2003) results, Del Gobbo $(2004,2005)$ shows that these relative clauses are still crucially different from canonical appositive relative clauses and proposes that they can modify pronouns and proper names because of a characteristic of Chinese relative clauses in general, i.e., because of their being "adjectival" (see Larson and Takahashi 2007 for a similar proposal on the basis of data from Japanese and Korean).

What this line of research leaves unexplained is exactly in what sense Chinese relative clauses are adjectival. In this paper, following Cinque's (2006a, 2008a) distinction between integrated appositive relative clauses and non-integrated ones, I claim that Chinese relative clauses are adjectival in the sense that they can only be of the integrated type. I claim that the typological difference between English, Italian and Chinese is due to the absence versus presence of the relative pronoun (as also proposed by Zhang 2001) and to which specific type of relative pronoun is contained in the relative clause.

The paper is organized as follows. In Sect. 2, I review Cinque's (2006a, 2008a) theory of relativization. In Sect. 2.1, I investigate the consequences of the application of such a theory to Chinese relative clauses, and in Sect. 2.2, I describe the differences in the structures for Chinese and English relative clauses. Section 3 is dedicated to the distinction between integrated and non-integrated appositives, and Sect. 3.1 deals with the structure of appositives in general. In Sect. 3.2, I show how Chinese appositive relatives can only be integrated, and in Sect. 3.3, I discuss the structure and derivation for both integrated and non-integrated appositives. In Sect. 4, I derive the typological differences between Chinese, English and Italian. Section 5 concludes the paper.

\section{A unified structure for relative clauses (Cinque 2006a)}

Aoun and Li (2003) showed that different structures and different derivations are available for relative clauses, both crosslinguistically and within the same language. In their system, they adopt both a raising and a matching derivation, and both a complementation structure and an adjunction structure are claimed to be necessary. 
Del Gobbo (2003), given the problems that a complementation structure faces in Chinese, exclusively adopts an adjunction structure. In her system, following Sauerland (1998), both a raising and a matching derivation are contemplated: raising is simply a special case of matching, where the internal head is identical to the external one and is elided by identity at LF.

Cinque (2006a, 2008a) proposes a very interesting unified analysis of relative clauses. In his system, all relative clauses originate prenominally, and both matching and raising are needed. ${ }^{1}$ The core of Cinque's (2003, 2008a) proposal is that a single structure underlies all types of relative clauses (externally headed postnominal, externally headed prenominal, internally headed, headless and correlative), in both the raising and the matching derivations. He proposes a structure in which the relative clause is merged prenominally, with every difference among the distinct relative clause types due to different derivational options. The prenominal merger of relative clauses, Cinque argues, is a consequence of a more general property of Universal Grammar. Cinque (2002, 2005a), on the basis of a general left-right asymmetry of natural languages, suggests that all elements found to the right of a lexical head $(\mathrm{N}(\mathrm{P}), \mathrm{V}(\mathrm{P})$, etc.) are not merged there, but come to be there as a consequence of the lexical head raising above them, merged in a left-hand specifier position. If so, Cinque reasons, relative clauses, like adjectives, are also merged prenominally in one of the NP's functional projections. Cinque (2003, 2008a, in prep.) suggests on the basis of cross-linguistic evidence that the Merge position of (finite) restrictive relative clauses is above the numeral, the adjectives, and the NP and below universal quantifiers, demonstratives and definite articles.

Cinque's system is appealing because it is able to derive externally headed postnominal relatives, externally headed prenominal ones, internally headed, headless (or free) relatives and correlatives from a unique structure of merge, encoding both raising and matching derivations. Notice also that the prenominal Merge of relative clauses makes a "matching" derivation possible within Kayne's (1994) Antisymmetry theory. This, as acknowledged in Cinque (2008b), may be a welcome result if both "raising" and "matching" derivations turn out to be necessary, as argued extensively in the literature (see Åfarli 1994; Sauerland 1998, 1999, 2003; Aoun and Li 2003; Del Gobbo 2003, among others).

Here, I will focus mainly on Cinque's (2003) proposal for externally headed relative clauses, both post-nominal and prenominal. Let's take an example like the following:

\section{(1) The expensive book that John bought is interesting.}

The analysis of integrated appositives Cinque (2006a) proposes is an extension of the analysis presented in Cinque (2003) for restrictive relatives. There he proposes that restrictive relatives are merged as IPs in the Specifier of a prenominal

\footnotetext{
1 Fukui and Takano (2000) have a similar proposal, in the sense that for them the differences between English and Japanese relative clauses all depend on the fact that the nominal head raises overtly in English but stays in situ in Japanese. In other words, they assume a head-final structure, and to derive the correct word order in English, they propose N-to-D movement.
} 
functional projection above the Specifiers which host attributive adjectives and numerals ${ }^{2}$ :

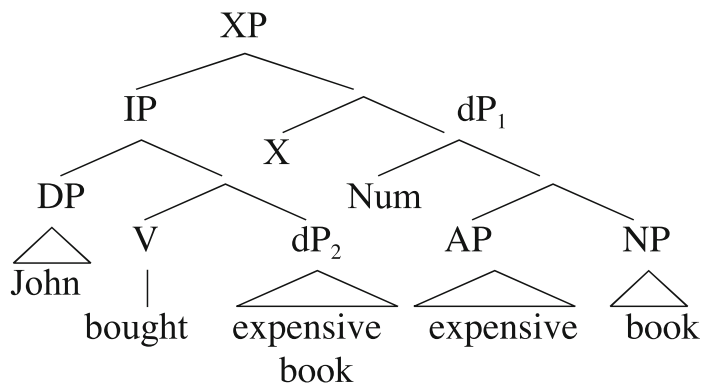

Following Kayne (1999, 2000, 2002), Cinque (2003, 2006a, 2008) proposes that the relative clauses' postnominal position in most $\mathrm{VO}$, and non-rigid $\mathrm{OV}$, languages is due to raising of IP to a higher licensing position ( $\mathrm{Spec}$ of $\mathrm{C}_{1}$ in the structure in (3) below), followed by merger of a (finite) complementizer $\left(\mathrm{C}_{2}\right.$ in (3) below), which attracts the head $\left(\mathrm{dP}_{2}\right.$ in the structure below). From this position, $\mathrm{dP}_{2}$ controls the deletion of $\mathrm{dP}_{1}$ in PF. Subsequently, $\mathrm{D}$ is merged. In Cinque's terms, this derivation represents a raising structure: the presence of reconstruction effects is captured by the fact that the head is directly linked to the trace within $\mathrm{IP}^{3}$ :

(3)

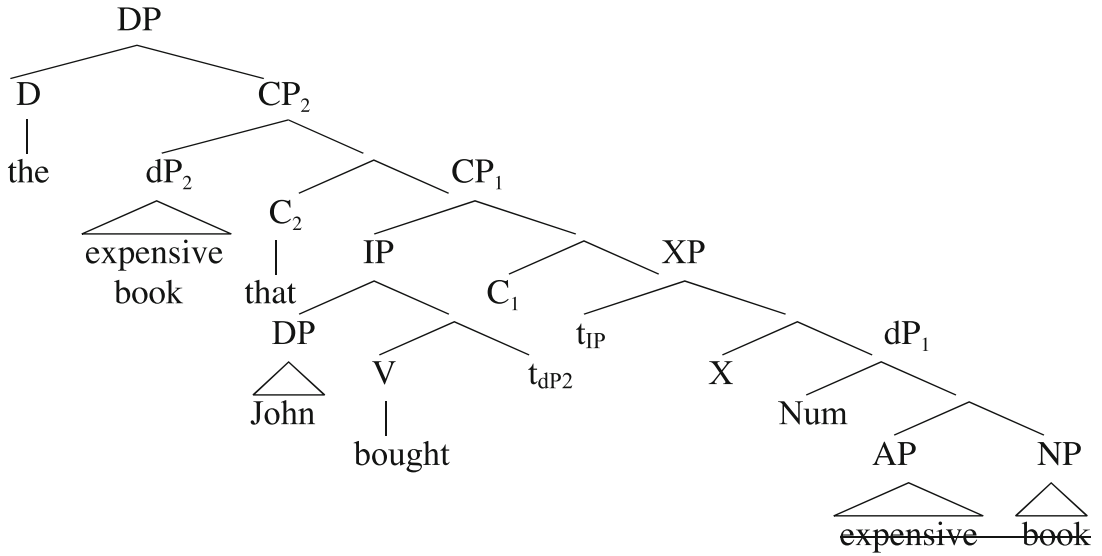

\footnotetext{
${ }^{2}$ One of the reviewers inquired about the relationship between $\mathrm{dP}$ and DP. According to Cinque (2003, in prep., 2006a, 2008a,b), dP includes numerals and attributive adjectives, while DP hosts determiners and demonstratives. As spelled out in the text, Cinque (2003, 2006a, 2008a) proposes that the merge position of a (finite) restrictive relative clause should be above the numerals, the adjectives and the NP and below universal quantifiers, demonstratives and definite articles.

${ }^{3}$ Notice that the movement of $\mathrm{dP}_{2}$ to the specifier position of $\mathrm{CP}_{2}$ constitutes a violation of CED (Condition on Extraction Domain, Huang 1982). Within the Antisymmetry framework, the problem is also present in OV languages, where the object of the verb is in a specifier position but nevertheless extraction from it is allowed. For an analysis of CED within Antisymmetry and a solution that could be extended to the case at hand, I refer the reader to Sheehan (2010).
} 
A terminological clarification is due at this point: following Cinque (2006a, 2008a), I make use of the terms "internal head" and "external head" of the relative clause. The internal head is the $\mathrm{dP}$ base-generated inside IP, i.e., in the structures I have been using, $\mathrm{dP}_{2}$. The external head is identical to the internal one and, according to Cinque (2003, 2006a, 2008a), it is base-generated as the complement of the functional projection that hosts the relative clause in its Spec. In the tree diagrams so far and in the remainder of the paper, it is marked as $\mathrm{dP}_{1}$. I also use the generic term "head of the relative clause," to refer to the nominal which on the surface is modified by the relative. In the structures we have seen so far and in the ones to come, the head can be either $\mathrm{dP}_{1}$ or $\mathrm{dP}_{2}$, i.e., it is the head that surfaces in $\mathrm{PF}$ and the one that controls the PF deletion of the other.

An alternative derivation proceeds as the one just described, but the internal head is base-generated as a relative pronoun and, after it raises, another complementizer is merged $\left(\mathrm{C}_{3}\right)$. This last complementizer attracts the external head, i.e., $\mathrm{dP}_{1}$. Once $\mathrm{dP}_{1}$ raises, it c-commands and therefore binds the relative pronoun in $\mathrm{dP}_{2}$ (that the relative pronoun has to be c-commanded by the head of the relative clause has been previously proposed by Cinque 1982; Fukui and Takano 2000, among others):

(4)

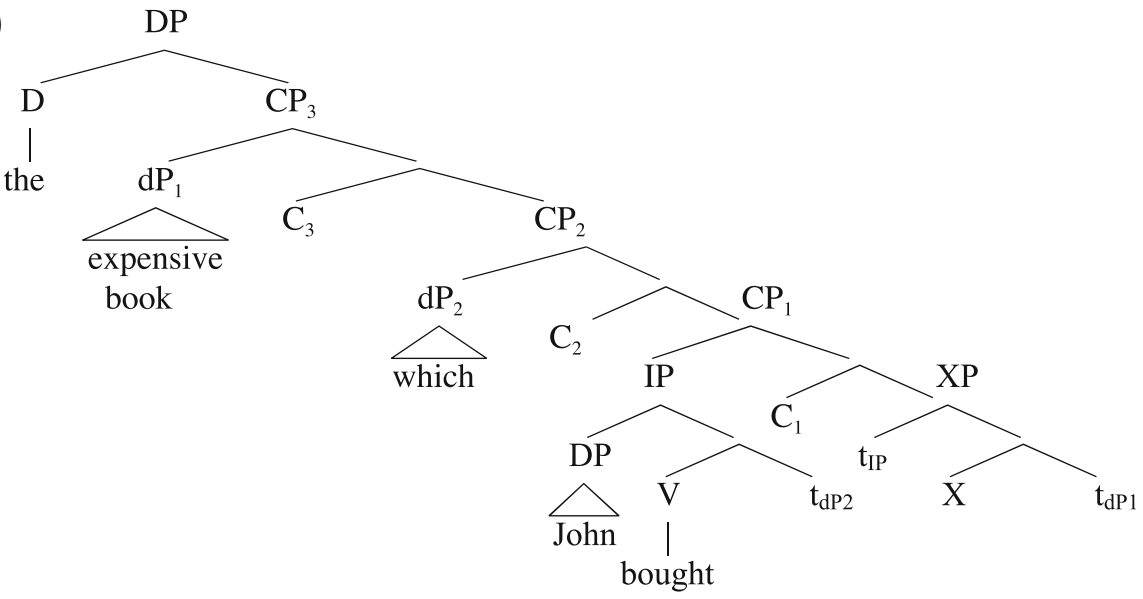

In this structure, which in this analysis is the equivalent of a matching structure, both $\mathrm{dP}_{1}$ and $\mathrm{dP}_{2}$ raise. The absence of reconstruction effects (noted, among others, by Aoun and $\mathrm{Li} 2003$ ) is captured by having the spelled-out head, i.e., $\mathrm{dP}_{1}$, not directly linked to the trace within IP.

\subsection{On the structure of Chinese relative clauses}

If we follow Cinque (2006a, 2008a) and adopt a uniform structure for both prenominal and post-nominal relative clauses, a possible derivation for prenominal relatives in Chinese implies movement of $\mathrm{dP}_{2}$ and of the entire remnant, i.e., $\mathrm{CP}_{1}$. Before getting into the details of the derivation, let me clarify that I follow Cheng $(1986,1997)$ and Paul (2006) in spirit and consider the modification particle de as a 
non-root complementizer. This analysis departs from Den Dikken (2006, 240-245) and Den Dikken and Singhapreecha (2004), who analyze de as a linker. More specifically, I analyze de as $\mathrm{C}_{1}$, in the tree diagram (6), for the nominal in $(5)^{4}$ :

(5) wo xihuan de xiaohuozi

I like Mod boy

'the boy I like'

(6)

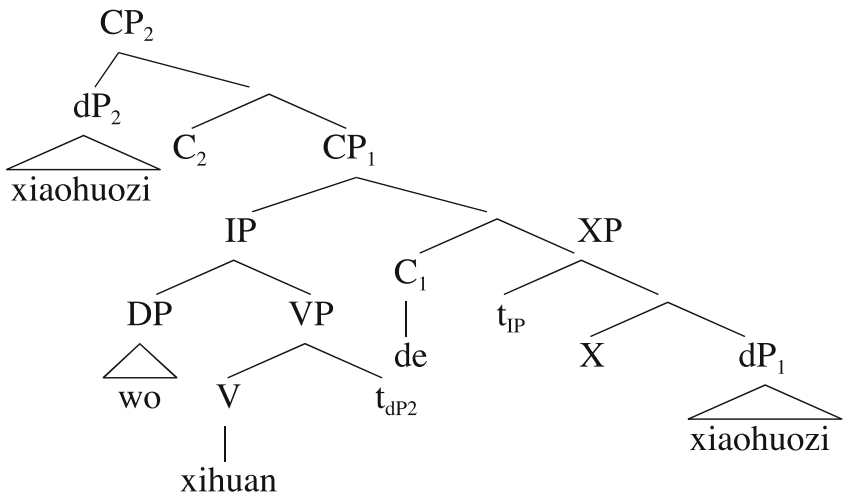

As in Italian and English, IP is base-generated in the Spec of a functional projection dominating $\mathrm{dP}_{1}$. It moves to the $\mathrm{Spec}$ of $\mathrm{CP}_{1}$ for licensing reasons. The internal head $\mathrm{dP}_{2}$ moves to the Spec of $\mathrm{CP}_{2}$, thereby accounting for the existence of island effects in Chinese relatives as well. ${ }^{5}$ At this point of the derivation, we have two options in order to derive the correct word order: one option involves raising $\mathrm{CP}_{1}$ and allowing $\mathrm{PF}$ deletion of $\mathrm{dP}_{2}$ by cyclic c-command (the notion of cyclic c-command is introduced in Huang 1982). The other option involves first allowing PF deletion of $\mathrm{dP}_{1}$ and then raising $\mathrm{CP}_{1}$. Both options seem to be allowed by the grammar: the first case qualifies as a matching structure, as the absence of reconstruction effects is

\footnotetext{
${ }^{4}$ For some support to analyze $d e$ as $\mathrm{C}_{1}$, see Cinque (2005b), where he says: "It is tempting to take the 'final complementizers' typical of 'rigid' OV languages to be the spell-out of the lower $\mathrm{C}$, the one which attracts the relative IP (and which is ordinarily not spelled-out in VO and 'non-rigid' OV languages)" (73).

5 The following examples, showing island effects, are taken from Huang et al. (2009):
}

(i) $*\left[\left[\right.\right.$ wo renshi [henduo $\left[\left[\mathrm{e}_{\mathrm{i}}\right.\right.$ xihuan $]$ de $]$ ren de $]$ na-ge nuhai $]$ I know many like Mod person Mod that-Cl girl

'the girl that I know many people who e $e_{i}$ likes'

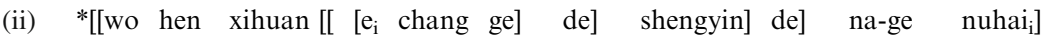
I very like sing song Mod voice Mod that- $\mathrm{Cl}$ girl

'the girl that I like the voice with which $\mathrm{e}_{\mathrm{i}}$ sings'

(iii) *[[wo kanjian le $\left[\mathrm{e}_{\mathrm{i}}\right.$ baba $]$ de] na-ge nuhai ${ }_{\mathrm{i}}$.

I see Asp father Mod that- $\mathrm{Cl}$ girl

'the girl that I saw [her] father' 
captured by not directly linking the head to the trace within IP; the second case qualifies instead as a raising structure, and the presence of reconstruction effects is accounted for by the direct link between the head and the trace within IP.

Let's look first at the matching structure in some detail. After the two derivation steps illustrated in (6), a new complementizer $\mathrm{C}_{3}$ is merged. $\mathrm{CP}_{1}$ raises to the Spec of $\mathrm{CP}_{3}$, and $\mathrm{dP}_{2}$ is deleted at $\mathrm{PF}$ as it is cyclically c-commanded by $\mathrm{dP}_{1}$ :

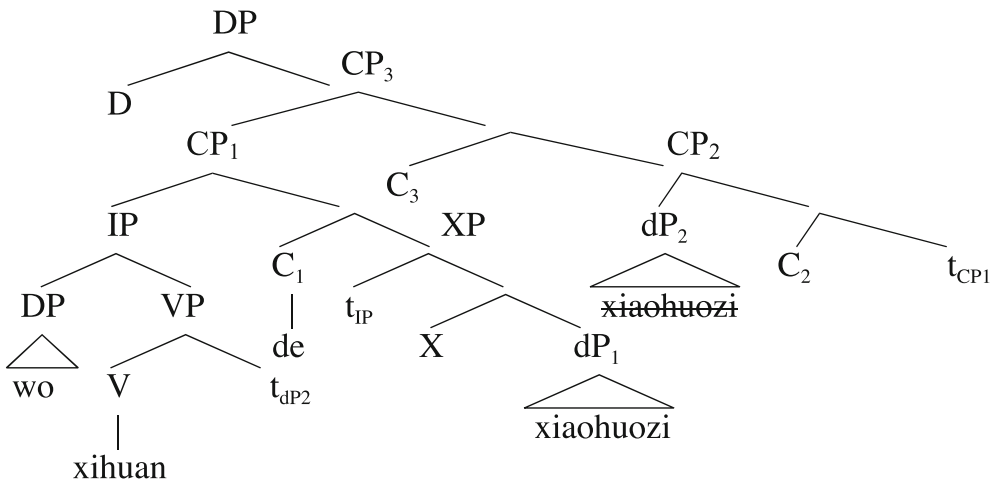

Before moving on to the raising structure, let's consider the role of cyclic c-command in the above derivation. In Chinese, as well as in English, a pronoun cannot c-command its antecedent:

$$
\begin{aligned}
& \text { * } \mathrm{Ta}_{\mathrm{i}} \text { kanjian le } \text { Zhangsan }_{\mathrm{i}} \\
& \text { he see Asp Zhangsan } \\
& \text { *'He saw Zhangsan } \\
& \text { '.' }
\end{aligned}
$$

But some other principle needs to account for the contrast in (9)-(10) below, and that principle has been identified as cyclic c-command by Huang (1982):
(9) * [DP $\mathrm{Ta}_{\mathrm{i}}$ de mama] xihuan Zhangsan ${ }_{\mathrm{i}}$. he Mod mother likes Zhangsan 'His $_{\mathrm{i}}$ mother likes Zhangsan ${ }_{\mathrm{i}}$ '

(10) [[CP Da le [DP $\mathrm{ta}_{\mathrm{i}}$ de mama $]$ de $]$ neige ren $]$ dui hit Asp he Mod mother Mod that man to Zhangsan $_{\mathrm{i}}$ hen bu keqi. Zhangsan very not polite 'The man that hit his $\mathrm{s}_{\mathrm{i}}$ mother was very impolite to Zhangsan ${ }_{\mathrm{i}}$.'

In (9), we surprisingly find that even though the pronoun inside the DP subject doesn't c-command the proper name in the object position, the sentence is ungrammatical. More strikingly, if the DP containing the pronoun is further 
embedded, grammaticality is restored, as exemplified in (10). In order to explain the facts above, Huang (1982) proposed the following definition:

(11) Cyclic c-command: A cyclic-c-commands B if and only if:

a. A c-commands $\mathrm{B}$, or

b. if $\mathrm{C}$ is the minimal cyclic node ( $\mathrm{NP}$ or $\mathrm{S}^{\prime}$ ) that dominates $\mathrm{A}$ but is not immediately dominated by another cyclic node, then $\mathrm{C}$ c-commands $\mathrm{B}$.

He furthermore proposed a language-specific condition on Chinese pronominal anaphora:

(12) Condition on Pronominal Anaphora in Chinese

A pronoun may not cyclic-c-command its antecedent.

Let's see how the notion of cyclic c-command plays a role in accounting for the facts in (8)-(10). In (8) the pronoun ta c-commands the proper name Zhangsan; therefore, it cyclic-c-commands it, and by the condition in (12), the two cannot be coreferential. In (9), the proper name Zhangsan cannot be coreferential with the pronoun $t a$ because even if the pronoun doesn't c-command the proper name, the minimal cyclic node (in Huang's terms, NP, in more recent terms, DP) that dominates the pronoun does c-command the proper name, and by (11b), this means that the pronoun does cyclic-c-command the proper name, yielding ungrammaticality. Notice that in (10), the minimal cyclic node that dominates the pronoun $t a$ is a DP. Since it is not immediately dominated by another cyclic node, it does qualify as $\mathrm{C}$ by (11b). But in (10), neither the pronoun itself not the DP that contains it c-command the proper name, hence the sentence is grammatical. Let's look at one additional case before returning to our matching structure in (7):

$$
\begin{aligned}
& \text { *[DP[DP } \mathrm{Ta}_{\mathrm{i}} \text { de mama] de pengyou xihuan Zhangsan }{ }_{\mathrm{i}} \text {. } \\
& \text { he Mod mother Mod friend likes Zhangsan }
\end{aligned}
$$

'His mother's friend likes Zhangsan $_{\mathrm{i}}$ '

Here, the first cyclic node dominating the pronoun $t a$ doesn't qualify as $\mathrm{C}$ by (11b); instead, the DP immediately dominating it does. That DP c-commands the proper name Zhangsan in (13) and, consequently, the pronoun ta cyclic-c-commands it, yielding ungrammaticality.

Just as cyclic c-command plays a role in pronominal anaphora in Chinese (and according to Huang 1982, also in Japanese; see pp. 392-393), I suggest that the notion of cyclic c-command also plays a role in PF deletion in Chinese. In other words, while c-command is the notion that, according to Cinque (2006a), drives the $\mathrm{PF}$ deletion of $\mathrm{dP}_{1}$ in (3), I claim that in the derivation of the matching structure for Chinese relative clauses, as depicted in (7), $\mathrm{dP}_{1}$ controls the $\mathrm{PF}$ deletion of $\mathrm{dP}_{2}$ by cyclic-c-commanding it. Let me slightly revise the notion of cyclic c-command: as has been common practice after Abney (1987), I propose to substitute NP with DP. 
Furthermore, we need to substitute $\mathrm{S}^{\prime}$ with $\mathrm{CP}$. Notice also that in (7), $\mathrm{CP}_{1}$, which I claim to be the relevant cyclic node, is indeed immediately dominated by another $\mathrm{CP}$ node, i.e., $\mathrm{CP}_{3}$. This node shouldn't qualify as a separate cyclic node, because, in the spirit of the Split-CP Hypothesis (see Rizzi 1997;Benincà and Poletto 2004, among others), all of the three CPs belong to the periphery of the same relative clause. Taking these observations into account, I propose to redefine cyclic ccommand as follows:

(14) Cyclic c-command

A cyclic-c-commands B if and only if:

a. A c-commands B

or

b. $\mathrm{C}$ is the minimal cyclic node (DP or $\mathrm{CP}$ ) dominating $\mathrm{A}$ that is not immediately dominated by another cyclic node not belonging to the same periphery, and $\mathrm{C}$ c-commands $\mathrm{B}$.

Given this new definition, in our structure in (7), the internal head $\mathrm{dP}_{1}$ cyclic-ccommands $\mathrm{dP}_{2}$, as the minimal cyclic node dominating it, i.e., $\mathrm{CP}_{1}$, c-commands $\mathrm{dP}_{2}$. By cyclic-c-commanding $\mathrm{dP}_{2}, \mathrm{dP}_{1}$ controls its deletion at PF. ${ }^{6}$

Let's analyze now the derivation of a raising relative clause, i.e., a relative clause where reconstruction effects are observed. Aoun and Li (2003) convincingly show that such reconstruction effects occur in a variety of cases in Chinese relativization. Here I will use one of their idiomatic examples:

(15) ta chi de cu

he eat Mod vinegar

Lit.: 'the vinegar he eats'

'His jealousy'

(modified from Aoun and Li 2003, 138)

After the two derivation steps illustrated in (6), for the raising structure, the raised $\mathrm{dP}_{2}$ c-commands (and hence also cyclic-c-commands) $\mathrm{dP}_{1}$, thereby allowing its deletion at PF. Only afterwards, $\mathrm{CP}_{1}$ raises to the Spec of $\mathrm{CP}_{3}$ :

${ }^{6}$ Huang (1982) also discusses relatives with resumptive pronouns, like the following one:

(i) wo song le ta yi-ben shu de nei-ge ren I send Asp him one-Cl book Mod that-Cl person 'the person to whom I send a book'

For such a relative, I propose the following structure:

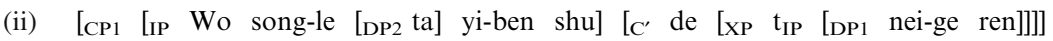

In this case, we have base generation of $\mathrm{DP}_{2}$, and the IP is the only phrase that moves. In the structure in (ii), ta does not cyclic c-command 'nei-ge-ren', because $\mathrm{CP}_{1}$ dominates $\mathrm{DP}_{1}$ and therefore cannot c-command it, correctly accounting for the absence of a Binding Principle $\mathrm{C}$ violation. 
(16)

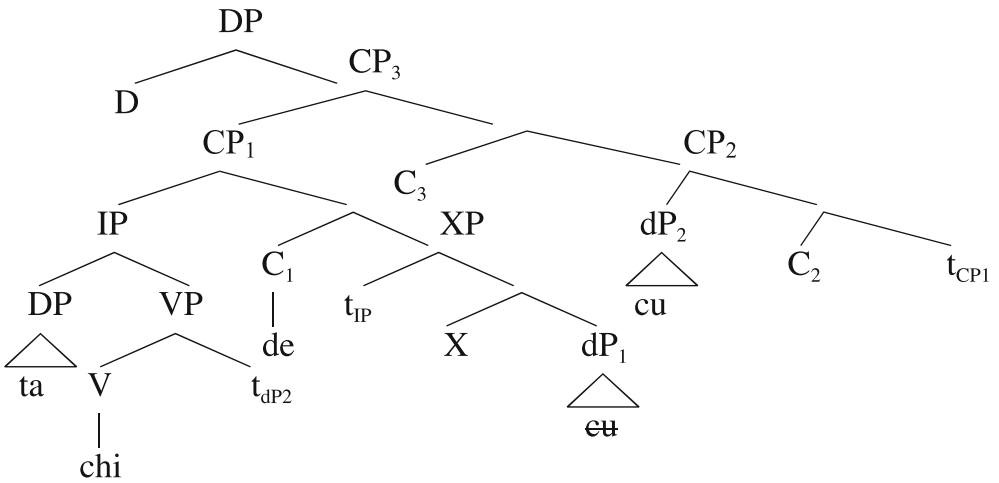

As explained before, the presence of reconstruction effects is captured by the fact that the head is directly linked to the trace ${ }^{7}$ within IP.

\subsection{On the structural differences between Chinese and English}

If we look closely at the structures and derivations outlined in the previous sections, we notice that the main differences between English (as representing here postnominal relative clauses) and Chinese (as representing here pre-nominal relative clauses) are:

1. In Chinese, $\mathrm{dP}_{2}$ is never realized as a relative pronoun;

2. $\mathrm{dP}_{1}$ never raises in Chinese; the remnant $\mathrm{CP}_{1}$ does.

Chinese is obviously not alone in not having a spelled-out relative pronoun. Downing $(1978,392)$ and Keenan $(1985,149)$ observe that no language with prenominal relatives displays genuine (initial) $w h$-pronouns. I propose to connect the unavailability of relative pronouns in Chinese-and typologically in all prenominal

7 Aoun and Li (2003) propose the following structures and derivations for Chinese relative clauses:

(1) NP relativization

a. $\left[\left[\mathrm{CP}\left[\mathrm{IP} \ldots\left[\mathrm{NP}_{\mathrm{i}}\right] \ldots\right] \text { [Head } \mathrm{NP}\right]_{\mathrm{i}}\right]$

- direct NP movement to Head

-reconstruction of the Head to $t$ possible

- sensitive to island conditions

This would correspond to the raising structure in the system I am developing here.

b. [[CP $\left.\mathrm{OP}_{\mathrm{i}}\left[\mathrm{IP} \ldots\left[\mathrm{NP}_{\mathrm{NP}} \operatorname{pronoun}_{\mathrm{i}}\right] \ldots\right]\left[\text { Head }_{\mathrm{NP}}\right]_{\mathrm{i}}\right]$

- Head base-generated and coindexed with an operator related to a base-generated RP

- reconstruction of the Head to RP impossible

- RP acceptable within an island

Possibly, this would translate in the structure postulated in fn. 6 .

(2) Adjunct relativization

$\left[\left[\mathrm{CP} \mathrm{OP}_{\mathrm{i}}\left[\mathrm{IP} \ldots\right.\right.\right.$ [PP $\left.\left._{\mathrm{i}}\right] \ldots\right]$ [Head $\left.\left.\mathrm{NP}\right]\right]$

- Head base-generated, OP movement to Spec of Comp

-reconstruction of the Head to $t$ impossible

- sensitive to island conditions

This would correspond to the matching structure. 
relative clauses - to the fact that relative pronouns need to be c-commanded and bound by the head of the relative clause (see Fukui and Takano 2000; Cinque 1982, among others). Therefore, I claim that while cyclic c-command is strong enough to allow $\mathrm{PF}$ deletion of $\mathrm{dP}_{2}$, it is not strong enough to allow binding and therefore licensing of a relative pronoun. So, in Chinese as well as in other languages with prenominal relative clauses, $\mathrm{dP}_{2}$ is never generated as a relative pronoun. ${ }^{8}$

This section concludes the discussion on the structure and derivation of restrictive relative clauses, both prenominal and post nominal. I turn now to the two different types of appositives identified in Cinque (2006a), i.e., integrated and nonintegrated ones.

\section{On integrated and non-integrated appositives}

Cinque (1982, 2006a), on the basis of evidence from Italian, proposes two structures for appositive relative clauses (henceforth, $\mathrm{ARCs}$ ):

1. integrated ARCs

2. non-integrated ARCs

He notices that in Italian (and French) there are substantial and interesting differences between ARCs with a spelled-out relative pronoun of the type il quale 'the which', and appositive relative clauses without such a pronoun but introduced by the complementizer $\operatorname{che}^{9}$ :

Gianni, il quale non è venuto a cena,...
Gianni the which not is come to dinner
'Gianni, who didn't come to dinner,...'

$$
\begin{aligned}
& \text { Gianni, che non è venuto a cena,... } \\
& \text { Gianni that not is come to dinner } \\
& \text { 'Gianni, who didn't come to dinner,...' }
\end{aligned}
$$

\footnotetext{
${ }^{8}$ A reviewer wondered whether there could be alternative accounts able to capture the unavailability of relative pronouns in Mandarin Chinese. Similar accounts do exists (see Fukui and Takano 2000 for Japanese, and Del Gobbo, in prep., for Mandarin Chinese and Japanese), but by resorting to them, we would lose the undeniable benefit of taking advantage of a theory that is well supported both theoretically and empirically. The proposal put forth by Cinque $(2003,2006 \mathrm{a}, 2008 \mathrm{a})$ and here defended allows us to derive all types of relative clauses using both a matching and a raising strategy and has a broad empirical basis.

${ }^{9}$ A fundamental difference between restrictives and appositives is related to binding. It is generally assumed that no element in the matrix can bind inside the appositives, as shown in the following notorious examples:
}

(i) a. [Every Christian $]_{\mathrm{i}}$ forgives a man who harms him $\mathrm{i}_{\mathrm{i}}$.

b. *[Every Christian $]_{\mathrm{i}}$ forgives John, who harms him $\mathrm{i}_{\mathrm{i}}$.

(Safir 1986)

Different accounts have been proposed, such as raising of the appositive at LF (Demirdache 1991; Del Gobbo 2003), invisibility of the appositive, either within the syntactic component (de Vries 2007, see also discussion in Sect. 3.1 below) or the semantic one (Potts 2005). I will refrain here from an account of the binding facts as they relate to the distinction between integrated appositives and non-integrated ones (for this, see Del Gobbo 2008-2009). 
In what follows, I will review some of the differences between integrated appositives and non-integrated ones, as pointed out by Cinque (2006a, 2008a). I refer the reader to Cinque for a full description of the facts.

A first difference concerns illocutionary independence. When the matrix is declarative, only the il quale-appositive can be either interrogative or imperative. The che-appositive behaves like a restrictive: it can only be declarative:
a. Tuo padre, il quale potrà mai perdonarci per quello your father the which will-be-able ever forgive-us for what che abbiamo fatto?, non si sarebbe mai comportato così. that have done not Refl. would-be ever behaved this-way 'Your father, by whom will we ever be forgiven for what we have done?, would have never behaved like that.'
b. *?Tuo padre, che potrà mai perdonarci per quello your father that will-be-able ever forgive-us for what che abbiamo fatto?, non si sarebbe mai comportato così that have done not Refl. would ever behaved this-way 'Your father, by whom will we ever be forgiven for what we have done?, would have never behaved like that?'

$\begin{array}{clllllll}\text { c. *Questa } & \text { è la } & \text { sola persona che potrà mai } \\ \text { this } & \text { is the } & \text { only person that will ever } \\ \text { perdonarci } & \text { per quello che abbiamo fatto? } & & \\ \text { forgive-us } & \text { for that } & \text { that have } & \text { done } & & \end{array}$

'This is the only person that will he ever manage to forgive us for what we have done?'

A second difference has to do with split antecedents: il quale-appositives, but not che-appositives, can have split antecedents ${ }^{10}$ :

a. Se Carlo non amava più Anna $_{\mathrm{i}}$, i quali $\mathrm{i}_{\mathrm{i}, \mathrm{j}} \mathrm{d}$ 'altra
if Carlo not love any-longer Anna the which of other
parte non si erano mai voluti veramente bene,
side not Recipr. were ever wanted really well
una ragione c'era.
a reason there was
'If C. was no longer in love with Anna, who at any rate never really
loved each other, there was a reason.'

\footnotetext{
${ }^{10}$ A reviewer points out that there are different types of split antecedent constructions. Specifically, he/ she brings to my attention the fact that in some split antecedent constructions, the two antecedents do not bear the same theta-role (this is the case for the example in (20) in the text), while in other cases the two antecedents do bear the same theta-role, as in the following example, from Zhang (2007):
}

(i) John saw a $\operatorname{man}_{\mathrm{i}}$ and Mary saw a woman ${ }_{\mathrm{j}}\left[\mathrm{who}_{\mathrm{i} \& \mathrm{j}}\right.$ were wanted by the police].

The reviewer shows that the split antecedent construction with the two antecedents bearing the same theta role is possible in Mandarin Chinese. I get back to this issue in Sect. 3.2. 
b. *Se Carlo $_{i}$ non amava più $A_{\text {nnna }}$, che $_{i, j}$ d'altra parte

if Carlo not love any-longer Anna that of other side non si erano mai voluti veramente bene,

not Recipr. were ever wanted really well

una ragione c'era.

a reason there was

* 'If Carlo was no longer in love with Anna, that at any rate never really loved each other, there was a reason.'

c. *Se il ragazzo non amava più la ragazza ${ }_{j}$ che $_{i+j}$ si if the boy not love any-longer the girl that Recipr. erano voluti bene, una ragione c'era. were wanted well a reason there was

*'If the boy no longer loved the girl that loved each other, there was a reason.'

(adapted from Cinque 2008a)

Third, il quale-appositives and che-appositives also differ with respect to the categorial nature of the antecedent that they can take. While che-appositives (and restrictives) take only nominal antecedents, il quale-appositives can take a large class of antecedents:

(21) a. Carlo lavora troppo poco. La qual cosa verrà Carlo works too little the which Thing will.be certamente notata. certainly noticed

'Carlo works too little, which will certainly be noticed.'

b. Carlo lavora troppo poco. *Che verrà certamente notato. Carlo works too little that will.be certainly noticed *'Carlo works too little, that will certainly be noticed.'

c. Carlo lavora troppo poco. *Di cui si è reso conto Carlo works too little of which Refl. is realized anche il suo principale. also the his boss

'Carlo works too little, which even his boss realized.'

(adapted from Cinque 1988)

(22) a. Maria è suscettibile. La qual cosa sua sorella di Maria is touchy the which thing her sister of certo non è. sure not is

'Maria is touchy, which her sister certainly is not.'

b. Maria è suscettibile. *Che sua sorella di certo non è. Maria is touchy that her sister of sure not is *'Maria is touchy, that her sister surely is not.' 


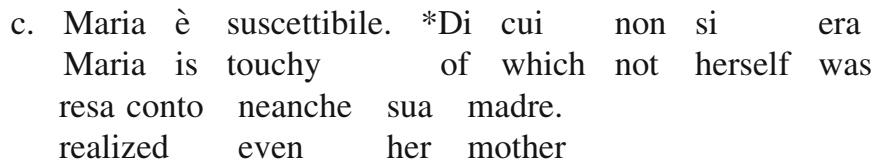

'Maria is touchy, which not even her mother realized.'

(adapted from Cinque 2008a)

According to Cinque (2006a, 2008a), an interesting typology of appositives follows from the proposal that two types exist: there may be languages with no appositives (as has been claimed, for example, by Aboh (2005) for Gungbe); languages with both types of appositives (Italian, French, and possibly Spanish, Catalan and (European) Portuguese, some Germanic languages, and Albanian); languages with only integrated appositives (possibly Northern Italian dialects, Chinese, Japanese, Basque, Yoruba, and Turkish) and, finally languages that display only non-integrated appositives (English, and Romanian). As Cinque (2006a, 2007) points out, the properties which had generally and traditionally been attributed to the appositive construction (because of the earlier focus on English) turn out to be only representative of the non-integrated type of appositive relative clauses.

\subsection{The structure and derivation of appositives}

For integrated appositives, Cinque (2006a, 2008a) proposes a structure that is minimally different from the one we have seen in Sect. 2 for restrictive relative clauses. In integrated appositives, the IP is merged in a specifier of a nominal projection dominating DP; i.e., outside the scope of the determiner or the demonstrative:

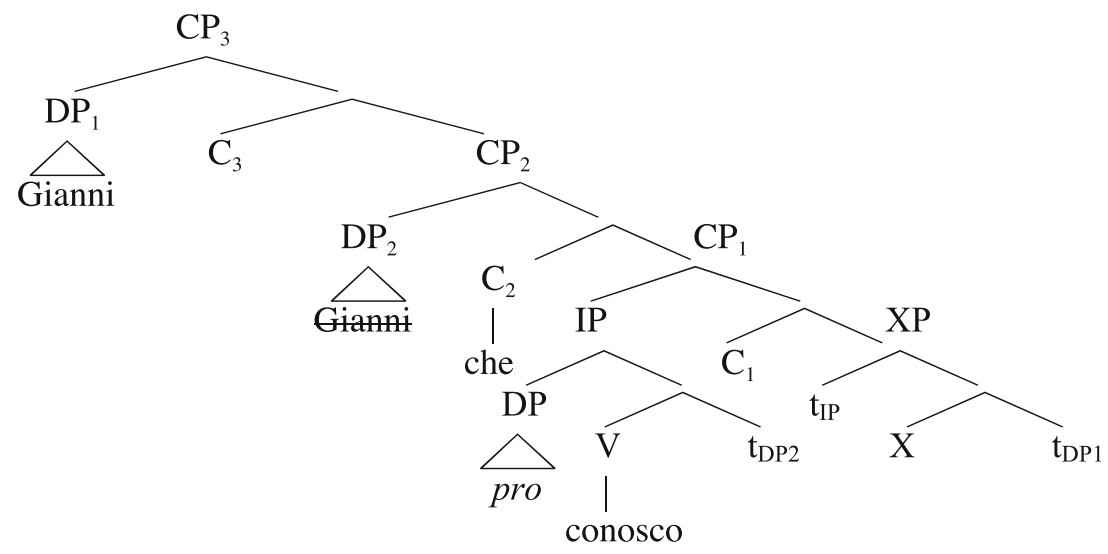

Also, since there are no reconstruction effects in either type of appositive in Italian, for the integrated ones Cinque (2006a, 2008a) adopts a matching structure, with raising of both $\mathrm{DP}_{1}$ and $\mathrm{DP}_{2}\left(\mathrm{DP}_{1}\right.$ raises and allows deletion of $\mathrm{DP}_{2}$ at $\mathrm{PF}$ by c-commanding it). As with the corresponding structure for restrictive relative clauses, the absence of reconstruction effects is captured by the fact that the head is not 
directly linked to the trace. The main difference with the restrictive relative clauses structure is that here the entire DP raises and not a smaller portion of it, i.e., dP.

For the non-integrated type, Cinque (2006a, 2008a) proposes an entirely different structure. His proposal builds on the idea that the non-integrated appositive construction seems to belong to what Williams (1977) called Discourse Grammar, and on the assumption that Kayne's (1994) Linear Corrispondence Axiom (LCA) holds of Discourse Grammar as well. Given this, linear precedence in a discourse must also reflect asymmetric c-command. One way to achieve this is to merge the linearly preceding sentence in the specifier of an empty head, which takes the following sentence as a complement. More concretely, the discourse fragment in (24) would have the structural representation in (25):

(24) John is no longer here. He left at noon.

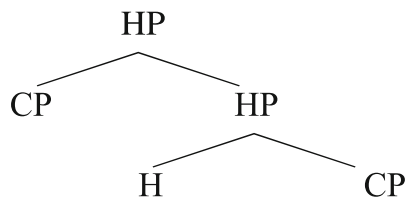

Cinque (2006a, 2008a) observes that discourse fragments do not consist of just concatenation of CPs, but other categories can also be concatenated (for example, $A$ pink shirt? I will never wear any such thing in my life!). It follows that a possible configuration for non-integrated appositives is one in which the DP head is concatenated with the appositive $\mathrm{CP}$, as in the following structure:

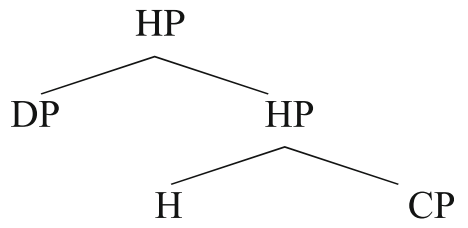

Crucial to this proposal is the assumption that the Discourse Grammar Head $\mathrm{H}$ blocks every Sentence Grammar relation between its specifier and complement, despite the asymmetric c-command relation existing between the two under the extension of the LCA to Discourse Grammar.

De Vries (2007) has a proposal that is similar to the one suggested by Cinque (2006a). He proposes that in general all parentheticals, and hence also appositive relative clauses, are structurally integrated with the host but not in a way that can be detected by c-command relations. Reasoning that dominance is a primitive relation in syntax, he concludes that the same should hold for parataxis (nonsubordination). Dominance, De Vries (2007) states, is used to represent subordination (if A is dominated by $\mathrm{C}$, it is subordinated to $\mathrm{C}$ ), but it cannot be stated in more primitive terms. The same seems to hold for paratactic construal, in the sense that it cannot be explained or derived by more primitive means; therefore, we need to accept it as a 
primitive of the grammar. Thus, he assumes that there is a primitive relation that represents nonsubordination, and one that represents subordination. Therefore, he proposes that two types of inclusion exist: 'd-inclusion' (as in dominance, which represents subordination), and 'b-inclusion' (as in behindance, which represents paratactic construal). As a consequence of there being two types of inclusions, there must be two types of Merge, which De Vries (2007) defines as follows:

d-Merge:

the input objects are d-included in the output object $\rightarrow$ syntactic hierarchy b-Merge:

the input objects are b-included in the output object $->$ paratactic hierarchy

Turning now to c-command, De Vries (2007) adopts a dynamic definition of c-command as the following one:

(28) C-command:

If Merge (A, B), then A c-commands B and all the constituents dominated by (i.e., d-included in) B.

It now becomes clear how parentheticals are immune from c-command ${ }^{11}$ : since in (28) c-command is defined over d-inclusion, it follows that b-inclusion blocks c-command relations. De Vries (2007) furthermore proposes to analyze appositions and appositive relative clauses as instances of specifying coordination. ${ }^{12}$ Let's look at one example of an appositive nominal:

$\begin{array}{lll}\text { (29) Joop, (ofwel) } & \text { onze } & \text { roorzitter. } \\ \text { Joop or } & \text { our } & \text { chairman } \\ \text { 'Joop, our chairman' } & \end{array}$

De Vries (2007) maintains that specification is syntactically comparable to coordination, and semantically, specification of A by B means that B adds information to A, i.e., it is nonrestrictive and also asymmetric, in the sense that the second conjunct specifies the first. Also, specifying coordination is often asyndetic (phonologically null); it does, however, often (according to De Vries 2007, always) trigger an intonational break. The appositive nominal and the appositive relative clause, then, are specifying conjuncts to their anchor, i.e., to the head of the relative clause. In order to represent the specifying coordinator, De Vries (2007) uses the symbol '\&:'. The most usual spell-out of $\&$ : is the phonological equivalent of a comma, and

\footnotetext{
${ }^{11}$ This is crucial because it has been claimed in the literature (see Safir 1986, among others) that no quantifier can bind a pronoun inside an appositive relative clause. More generally, appositives seem to be invisible to binding, as, for example, they cannot license parasitic gaps (Engdahl 1983), and anaphors within them cannot be bound (Giorgi 1984) (see fn. 9).

12 More precisely, De Vries (2006) argues that an appositive relative clause is a semi-free relative in apposition to the overt antecedent. Here, I will focus mainly on the formal syntactic representation of apposition, and will not endorse the proposal that appositives are semi-free relatives (for some arguments against this approach, see Del Gobbo 2003; Cinque 2006a, fn. 36).
} 
appositions are represented as in (30), where $\mathrm{DP}_{1}$ is the anchor or head of the relative, and $\mathrm{DP}_{2}$ is the apposition or the appositive relative clause:

$$
\text { [\&:P } \left.\mathrm{DP}_{1}\left[\&: ;: \mathrm{DP}_{2}\right]\right]
$$

In order to insure that the appositive relative clause is not affected by c-command, De Vries (2007) proposes that \&: and $\mathrm{DP}_{2}$ are b-included instead of d-included (the star next to \&:' in the following tree diagram indicates that its daughters are b-included instead of d-included):

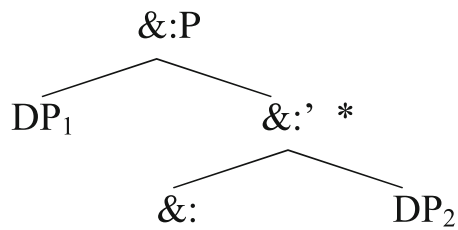

In (31) $\mathrm{DP}_{1}$, the head of the relative clause c-commands \&:', but it cannot c-command its constituents, as those are not dominated by (i.e., d-included in) \&:', they are solely b-included. It follows that no other element in the structure in which (31) is embedded can c-command the appositive.

It is worth noting at this point the striking similarity with the structure proposed by Cinque (2006a, 2008a) and represented by the tree diagram in (26) above. In fact, Cinque acknowledges in a footnote that his analysis is reminiscent, among other studies, of the "ColonP" analysis advanced in Koster (2000) for both restrictives and appositives and to the ParatacticP analysis suggested by Gärtner (2001) for V2 relatives in German-studies that have also influenced De Vries's (2002, 2006, 2007) work. One of the main differences between the proposal behind Cinque's structure in (26) and De Vries' structure in (31) is how they account for the appositives' invisibility to c-command. Cinque (2006a, 2008) proposes to assume that the Discourse Grammar Head H blocks every Sentence Grammar relation between its specifier and complement, including internal Merge, Agree, Binding, etc. This seems to be too strong, as we need to account, for example, for the fact that the anchor (or head) agrees with the relative pronoun, although in some cases this happens more loosely than within restrictives-see split antecedents, and number “dis"-agreement examples, observed by Cinque (2006a, 2008a). De Vries's system has the advantage of accounting for both the invisibility to c-command effect and the agreement facts. Notice that both proposals immediately account for postnominal appositive relative clauses, but it is not clear how they can be extended to account for prenominal appositive relative clauses or, I should say, for the unavailability of canonical appositives in languages that relativize prenominally (see also Citko 2008 on this).

Del Gobbo (2007) proposes to treat appositive relative clauses as an instantiation of E-type anaphora. Like Cinque (2006a) and others, she assumes that the appositive and the matrix clause that contains it represent a piece of discourse. Using data that shows that no backward anaphora is allowed in discourse, she reasons that an E-type 
pronoun needs to linearly follow its antecedent. For appositive relative clauses, this means that the appositive relative pronoun needs to follow its head; in other words, no prenominal relative clause can be a true appositive.

Differently from Cinque (2006a) and De Vries (2007), Del Gobbo (2007) assumes that a discourse structure is made up of two sentences (two CPs) in relationship of sisterhood with each other. She proposes that the appositive relative clause is merged in narrow syntax to the nominal it modifies, and that is where it occurs at PF, but at LF the appositive is moved and merged as a sister to the matrix clause. Crucial to this approach is the idea that even though PF and LF do not communicate with each other in syntax, at the discourse level the computational component is able to access both interfaces. The idea that PF and LF could both be accessed at the same time is obviously controversial. The leading assumption regarding the architecture of language is the T-model. In this view, the interface of the computational system with the conceptual/intentional system must be only through LF, and PF should not be accessible. PF and LF should be separate and independent. But there are empirical domains that pose a challenge to this view. One is Focus. And to account for properties of focus structure, Reinhart (2006) proposes two possible scenarios. In the first, most controversial one, PF is legible to the inference systems, "in the sense that all information regarding the syntactic tree that is needed for constructing semantic representation (propositions) is obtained through PF-coding" (Reinhart 2006, 138). In other words, LF is recoverable from PF. The second scenario doesn't force a departure from the T-model. Reinhart (2006, 139) envisages a system whereby "the inputs to the inference (semantic) system are $<\mathrm{LF}, \mathrm{PF}>$ pairs, so it is only in restricted cases, like focus identification, that the relevant information is coded at PF." Del Gobbo (2007) adopts such a line of reasoning and identifies (canonical) appositive relative clauses as one of those restricted cases for which relevant information is coded at PF. This approach has the advantage of accounting for some appositives that are surprisingly able to modify quantified nominals. I will not go into the details of the data here and refer the interested reader to Del Gobbo (2007). The other main difference between this theory and the ones put forth by Cinque (2006a) and De Vries (2007) is that within this theory it is expected that prenominal relative clauses cannot be truly appositive.

In the next section I investigate Chinese relative clauses as an instantiation of prenominal relative clauses, and in Sect. 3.3, I put forth my proposal for nonintegrated appositive relative clauses.

\subsection{On Chinese appositive relative clause}

Chinese relative clauses are prenominal, they lack relative pronouns, and they have been analyzed as giving rise to both raising and matching structures (Aoun and Li 2003). What is of interest to us here is that they can modify proper names or pronouns. Once the proper name (or pronoun) denotes an individual that is unique in the universe of discourse, we know that semantically the modifying relative clause is appositive. Here are some examples: 
(32) Xianglai jiu bu ai du shu de Xiaoming xianzai always then not love study book Mod Xiaoming now ye kaishi du qi shu lai le. also begin study begin book come Asp Lit.: 'Xiaoming who does not love to study now also has begun to study.' (adapted from Lin 2003)

(33) Yongyou wuqian nian youjiu lishi wenhua de Zhongguo possess five.thousand year age.old history culture Mod China zhongyu juexing le. finally awaken Asp

Lit.: 'China which possesses age-old history and culture, is finally awakening.' (adapted from Lin 2003)

(34) Tang zai bing-chuang-shang de Lu Xun hai zai xie wenzhang. lie at sick-bed-on Mod Lu Xun still Asp write article

Lit.: 'The Lun Xun who was in a patient-bed was still writing articles.'

(Tsao 1986: 33)

What's intriguing about such relatives is that other than modifying a proper name (or a pronoun), they do not share any other of the traits that are traditionally ascribed to appositive relative clauses (see Del Gobbo 2003; Zhang 2001 for more such examples). Here, I will focus on the characteristics individuated by Cinque (2006a, 2008a).

First, let's consider illocutionary independence. We saw before that in Italian, when the matrix is declarative, only the il quale-appositive can be either interrogative or imperative. The che-appositive behaves like a restrictive: it can only be declarative. To check the facts in Chinese, let me start with a sequence of two sentences, one declarative and one interrogative:

a. Zhangsan juedui bu hui zheme zuo. Ta hui bu Zhangsan absolute not able this way do he able not hui yuanliang women?

able forgive us

b. Zhangsan juedui bu hui zheme zuo. Ta hui Zhangsan absolute not able this way do he able yuanliang women ma?

forgive us Q

'Zhangsan could never behave this way. Will he forgive us?'

Now, I attempt to make the interrogative clause modify the proper name Zhangsan as a relative clause: 
(36)

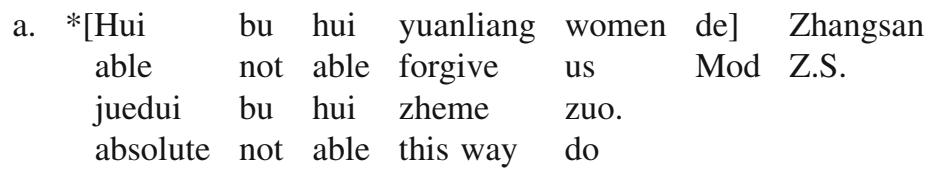

b. *[Hui yuanliang women ma de] Zhangsan juedui bu able forgive us Part. Mod Z.S. absolute not hui zheme zuo. able this.way do

As expected, both sentences result in ungrammaticality.

A reviewer brought to my attention the following sentence:
$\mathrm{Ni}$ zui xihuan shenme shihou kan-qi-lai de ta?
you most like what time see-lift-come Mod she
Lit.: 'When do you most like the appearance of her?'

$\mathrm{He} / \mathrm{she}$ maintains that the example in (37) represents evidence that a relative clause modifying a pronoun can be interrogative. Notice that with closer scrutiny this is not the case. Potential answers to (37) can be:
a. Shueijiao de shihou kan-qi-lai de ta. sleep Mod time see-lift-come Mod her Lit.: 'The appearance of her when she's sleeping.'
b. Renzhen gongzuo de shihou kan-qi-lai de ta. seriously work Mod time see-lift-come Mod her 'The appearance of her when she's working hard.'
c. Anjing de shihou kan-qi-lai de ta. Quiet Mod time see-lift-come Mod her 'The appearance of her when she's quiet.'

Notice that in (37) the wh-word shenme shihou takes wide scope, providing the interpretation 'when is the time $\mathrm{x}$ such that you like the appearance of her at time $\mathrm{x}$ '. This means that the whole matrix clause is interrogative and not the embedded appositive relative clause. As a matter of fact, if we embed $w h$-words inside appositive relative clauses in Chinese, we either get an indefinite reading or the sentence results in ungrammaticality. Here is an example where the $w h$-word is inside the relative clause and can only have the interpretation of an indefinite:

(39) $\mathrm{Ni}$ na-ge [shenme shihou zou-diu] de baba juedui you that-Cl what time walk-lost Mod father absolute bu hui zheme zuo. not able this.way do

'That father of yours, who got lost sometime ago, would never do something like this.' 
In the following two examples, instead, the addition of the $w h$-word inside the relative clause renders the sentence ungrammatical:

(40) *Wo xuan le dedao le duoshao piao de Zhangsan. I choose Asp obtain Asp how.many tickets Mod Zhangsan Int.: 'I chose Zhangsan, who received how many votes?'

(41) *Wo xihuan qu nali de Zhangsan. I like go where Mod Zhangsan Int.: 'I like Zhangsan, who went where?'

To summarize, it may be misleading to take the examples in (36) to show that a relative clause cannot be interrogative in Mandarin Chinese. This is because final particles such as ma (in (36b)) are a root phenomenon and are never allowed in embedded clauses; in other words, yes-no questions with ma in Mandarin Chinese are restricted to matrix clauses. We know that A-not-A questions (the form used in (36a)) appear both in direct and indirect questions, as shown in the following examples from Huang et al. (2009):

(42)

Zhangsan bu xiaode ni lai bu lai. Zhangsan not know you come not come

'Zhangsan does not know whether you will come or not.'

(43) $\mathrm{Ni}$ juede ta hui bu hui lai ne?

you think he can not can come Q

'Do you think he will come or not?'

But Huang et al. (2009) report that if the A-not-A is embedded in an island, such as a relative clause, the direct question reading is unavailable:

$$
\begin{aligned}
& \text { *Ni bijiao xihuan lai bu lai de na-yi ge ren (ne)? } \\
& \text { you more like come not come Mod that-one } \mathrm{Cl} \text { person Q } \\
& \text { Int.: 'Do you prefer the person that will come or the one who will not?' }
\end{aligned}
$$

The sentence in (44) is ungrammatical because in order to get the wide scope reading, the A-not-A form should undergo movement at LF, and in (44) this is blocked by the ECP. In order to embed the A-not-A form inside an island, Huang et al. (2009) claim that an indirect-question interpretation is required, as when the island clauses are selected by appropriate verbs or nouns:

(45) [Ta lai bu lai] yidiar dou mei guanxi. (*ne?).

he come not come at.all all no matter Q

'Whether s/he comes or not does not matter at all.' 
(46) Wo xiang taolun [ta lai bu lai de wenti]. (*ne?). I want discuss he come not come Mod question Q 'I want to discuss the question of whether he comes or not.'

The problem with our example in (36a), repeated below, is that the A-not-A form cannot take wide scope and that it is not selected by an appropriate verb or noun:

$\begin{array}{cllllll}\text { a. *[Hui } & \text { bu } & \text { hui } & \text { yuanliang } & \text { women } & \text { de }] & \text { Zhangsan } \\ \text { able } & \text { not } & \text { able } & \text { forgive } & \text { us } & \text { Mod } & \text { Z.S. } \\ \text { juedui } & \text { bu } & \text { hui } & \text { zheme } & \text { zuo. } & & \\ \text { absolute } & \text { not } & \text { able } & \text { this way } & \text { do } & & \end{array}$

The examples that more strongly show that an appositive relative clause in Mandarin Chinese cannot be interrogative are the ones in (39) through (41). We know that a $w h$-word can have scope over the matrix clause or only over the embedded clause, as the following examples from Huang et al. (2009) illustrate:

Zhangsan yiwei Lisi mai le shenme?
Zhangsan thinks Lisi buy Asp what
'What does Zhangsan think Lisi bought?'

Zhangsan xiang-zhidao Lisi mai le shenme.
Zhangsan wonder $\quad$ Lisi buy Asp what
'Zhangsan wonders what Lisi bought.'

If an appositive relative clause in Mandarin Chinese could be interpreted as interrogative, then in the sentences (39) through (41) the wh-word should be able to take scope over the relative clause, but we have already seen that this is not possible. I therefore conclude that the evidence provided here shows that appositive relative clauses in Mandarin Chinese cannot be interrogatives, differing therefore in a crucial way from appositives in Italian and English.

We turn now to the issue of split antecedents. We saw that in Italian, il qualeappositives, but not che-appositives, can have split antecedents. In Chinese, split antecedents are allowed inter-sententially:

(49) Zhangsan $_{i}$ jinlai le, Lisi $_{j}$ zou le. Tamen ${ }_{i+j}$ bu xihuan Xiaoyu. Z.S. enter Asp Lisi exit Asp they not like Xiaoyu 'Zhangsan entered. Lisi left. They don't like Xiaoyu.'

But if we attempt to have the second sentence in (49) as a relative clause modifying Zhangsan syntactically and both Zhangsan and Lisi semantically, ungrammaticality arises:

$\begin{array}{llllllll}* \mathrm{Op}_{\mathrm{i}+\mathrm{j}} & \text { bu } & \text { xihuan } & \text { Xiaoyu } & \text { de } & \text { Zhangsan }_{\mathrm{i}} & \text { jinlai } & \text { le, } \\ & \text { not } & \text { like } & \text { Xiaoyu } & \text { Mod } & \text { Zhangsan } & \text { enter } & \text { Asp } \\ \text { Lisi }_{j} & \text { zou } & \text { le. } & & & & & \\ \text { Lisi } & \text { exit } & \text { Asp } & & & & & \end{array}$


If meaningful at all, (50) simply means: 'The Zhangsan that doesn't like Xiaoyu entered, Lisi went out'.

As initially addressed in footnote 10 , a reviewer brought to my attention the fact that there can be different types of split antecedent constructions. Specifically, in the one illustrated in the Italian example in (20a) from Cinque (2008)-repeated below-the two antecedents have different theta roles:

$$
\begin{aligned}
& \text { a. Se Carlo non amava più } \text { Anna }_{\mathrm{j}} \text {, i } \text { quali }_{i, j} \mathrm{~d} \text { 'altra } \\
& \text { if Carlo not love any-longer Anna the which of other } \\
& \text { parte non si erano mai voluti veramente bene, } \\
& \text { side not Recipr. were ever wanted really well } \\
& \text { una ragione c'era. } \\
& \text { a reason there was } \\
& \text { 'If C. was no longer in love with Anna, who at any rate never really } \\
& \text { loved each other, there was a reason.' }
\end{aligned}
$$

Relative clauses with split antecedents were first noticed by Ross and Perlmutter (1970). The following examples are from Zhang (2007):

(51) a. Mary met a $\operatorname{man}_{\mathrm{i}}$ and John met a woman ${ }_{\mathrm{j}} \mathrm{who}_{\mathrm{i} \& \mathrm{j}}$ knew each other $\mathrm{i}_{\mathrm{i} j}$ well.

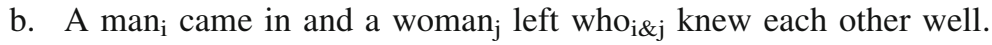

c. The house has a room $i$ and the shop has a cellar which $_{i \& j}$ are joined by a small underground passageway.

Even though the reviewer agrees with me on the ungrammaticality of the sentence in (50), he/she points out that as far as the antecedents share the same theta roles, such sentences can be grammatical in Mandarin Chinese, as illustrated by the following example:

$$
\begin{array}{lllll}
\text { Fenbie dou ai } & \text { guo Xiaoyu } & \text { de } & \text { Zhangsan } & \text { jiagei le } \\
\text { separately all love } & \text { Asp Xiaoyu } & \text { Mod Zhangsan } & \text { marry-Asp } \\
\text { Wangwu, } & \text { Lisi } & \text { jiagei le } & \text { Houliu. } & \\
\text { Wangwu, } & \text { Lisi } & \text { marry-Asp } & \text { Houliu. } & \\
\text { 'Zhangsan } & \text { married Wangwu and Lisi } & \text { married Houliu who } \\
\text { }_{i+j} & \text { both had loved } \\
\text { Xiaoyu.' } & &
\end{array}
$$

Although the reviewer doesn't mention an existing analysis for sentences such as the one in (52), he/she points my attention to Zhang (2007). Zhang claims that the two antecedents of relative clauses with split antecedents are originally two conjuncts of a coordinate nominal. She proposes that each has undergone a sideward movement, involving a move from the original working site to a new one. The two nominals take part in the construction of a coordinate clausal complex. In the old working site, a complex nominal is constructed, in which the relative clause takes the remnant coordinate nominal as its antecedent. Finally, the complex nominal adjoins to the coordinate clausal complex. I believe a similar analysis can be made to work in order to explain the grammaticality of examples such as (52). Crucial for 
us here is the fact that the construction Zhang studies has a number of restrictions, the most important of which is that the two antecedents need to share the same theta-role. More generally, in order for sentences with split antecedents to be grammatical, they have to be parallel, in a sense that I will not make precise here (for details, see Zhang 2007, section 5). The sentence provided by the reviewer and reproduced in (52) respects such requirement for parallelism, while the one in (49) doesn't seem to. It is likely that sentences like (52) can be analyzed along the lines suggested by Zhang for English. What is relevant for us is that it is the other type of split antecedent relative that is not allowed in Mandarin Chinese. We have seen that in Italian it is grammatical for an appositive relative clause to have two split antecedents, even when they do not share the same theta-role. Under these conditions, similar examples in Mandarin Chinese turn out to be ungrammatical. Let me start with two sentences in a piece of discourse:

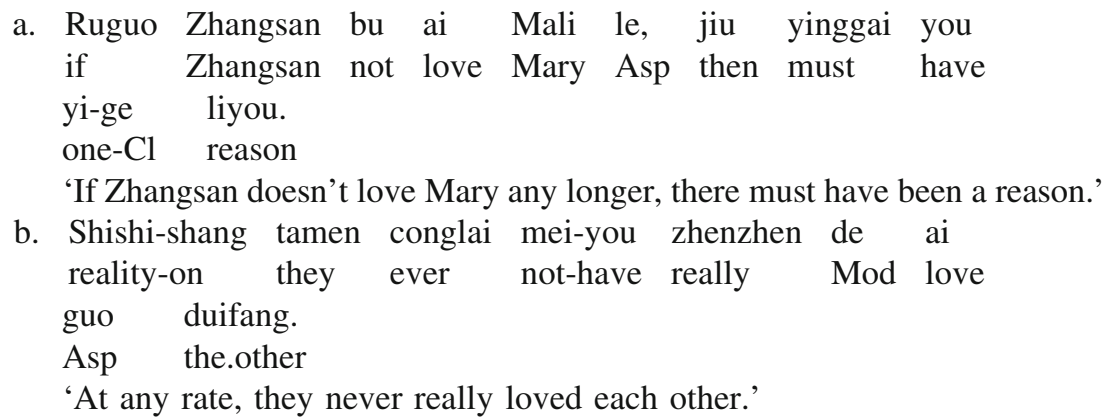

If we try to convey what expressed in the two sentences in (53) using a simple sentence and a relative clause — as we did with the Italian example in (20) — the outcome is ungrammatical:

$\begin{array}{lllllll}* \text { Ruguo } & \text { [conglai mei-you zhenzhen de ai guo duifang de] } \\ \text { if } & \text { even } & \text { not-have } & \text { really } & \text { Mod love Asp the.other Mod } \\ \text { Zhangsan bu ai Mali le, jiu yinggai you yi-ge liyou. } \\ \text { ZS } & \text { not love M. Asp then must have one-Cl reason. }\end{array}$

$\begin{array}{llllllll}\text { *Ruguo } & \text { Zhangsan } & \text { bu } & \text { ai } & \text { [conglai } & \text { mei-you } & \text { zhenzhen de } \\ \text { if } & \text { Zhangsan } & \text { not } & \text { love } & \text { ever } & \text { not-have } & \text { really } & \text { Mod } \\ \text { ai } & \text { guo } & \text { duifang } & \text { de] } & \text { Mali } & \text { le, } & \text { jiu } & \text { yinggai } \\ \text { love } & \text { Asp } & \text { the.other } & \text { Mod } & \text { Mary } & \text { Asp } & \text { then } & \text { must } \\ \text { you } & \text { yi-ge } & \text { liyou. } & & & & & \\ \text { have } & \text { one-Cl } & \text { reason. } & & & & & \end{array}$

The sentences in (54) and (55) above are ungrammatical, in the intended reading of 'If Zhangsan doesn't any longer love Mary, who at any rate never really loved each other, there must be a reason'. The ungrammaticality of the sentences in (54) and 
(55) shows that appositive relative clauses in Mandarin Chinese are not able to take split antecedents when these do not share the same theta-role. ${ }^{13}$

When we consider the categorial nature of the antecedent, we notice that in Chinese, a relative clause can modify only a nominal; it cannot modify adjectival phrases, verbal phrases, prepositional phrases or entire sentence:

${ }^{13}$ Another reviewer also suggests that split antecedents are possible for Chinese appositive relative clauses. To support his/her view, he/she provides the following examples:

(i) Zhangsan dui [[cengjing yiqi gongzuo guo de] Lisi] hen bu man. Zhangsan to ever together work Asp Mod Lisi not very satisfied 'Zhangsan was very dissatisfied with Lisi, who used to work together with him.'

The reviewer reasons that in (i) above, the adverb yiqi 'together' would force the split antecedent reading. But notice that this is not necessarily the case. Even though yiqi 'together' is a collective adverb, it can occur in a sentence where only one nominal is present, and such a nominal refers to a singular individual. Here is an example:

(ii) Hai: Kuai kaoshi le. Wo dasuan xiaowu qu tushuguan wenxi, ni Hai: almost test Mod I plan afternoon go library review, you $\frac{\text { yao }}{\text { want }} \frac{\text { yiqi }}{\text { together }} \frac{\text { lai }}{\text { come }} \frac{\mathrm{ma}}{\mathrm{Q}}$

'Hai: “It's almost time for exams. I'm planning to go to the library this afternoon to start reviewing my course notes. Do you want to go with me?"

(Lai, 2008: 245)

Notice that in the underlined sentence in (ii), yiqi occurs when the only nominal expressed is $n i$, 'you (2ps)'. What seems to be implied is the prepositional phrase gen wo, 'with me', which is probably recoverable given that the referent denoted by $w o$, 'me' is introduced with the subject of the preceding sentence. Something similar happens in (i), where gen ta is omitted, likely because the referent $t a$ would denote is already introduced by Zhangsan, the subject of the sentence. The following sentences illustrate the same point:

(iii) Zhangsan hen xihuan cengjing yiqi gongzuo guo de Lisi. Zhangsan very like already together work Asp Mod Lisi

'Zhangsan likes Lisi a lot, who already worked together with him.'

(iv) Ruguo wo mingtian yao qu tushuguan, ni yao yiqi lai ma? if I tomorrow want go library you want together come MA

'If I go to the library tomorrow, do you want to come with me?'

(v) Zhangsan zuotian qu le tushuguan, Lisi (ye) yiqi qu le.

Zhangsan yesterday go Asp library, Lisi (also) together go Mod

'Zhangsan yesterday went to the library, Lisi also went with him.'

My native speaker consultant pointed out to me that if the order of the sentences in inverted, ungrammaticality arises, as in the following example:

(vi) *Lisi yiqi qu le, Zhangsan zuotian qu le tushuguan.

Lisi together go Asp, Zhangsan yesterday go Asp library

To conclude, the example in (i) provided by the reviewer does not show that appositive relative clauses in Mandarin Chinese can have split antecedents. It shows instead that the collective adverb yiqi is able to appear in a sentence where only one referent is instantiated, provided that the other referent is already introduced in the discourse. 
(56) a. * Zhangsan hen [CP Lisi conglai jiu bu] de [AP congming]. Zhangsan very Lisi ever just not Mod smart

b. Zhangsan hen congming. Lisi conglai jiu bu congming. Zhangsan very smart Lisi ever just not smart. 'Zhangsan is intelligent. Lisi never has been.'

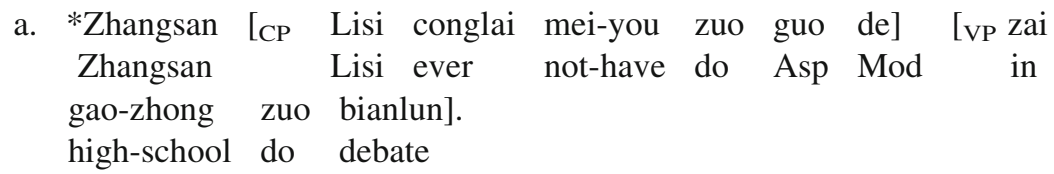

b. Zhangsan zai gao-zhong zuo guo bianlun Lisi conglai mei-you Zhangsan in high-school do Asp debate. Lisi ever not-have zuo-guo. do Asp

'Zhangsan debated in high school, which Lisi never did.'

(58) a. Wo [PP cong 1992 dao 1993] zai Beijing Yuyan Xueyuan I from 1992 to 1993 in Beijing Language Institute xuexi Hanyu. Tai duan-le.

study Chinese too short-LE

'From 1992 till 1993 I studied Chinese at the Language Institute in Beijing. It was too short (a period of time).'

b. *Wo [CP tai duan-le de] [pP cong 1992 dao 1993 zai I too short-LE Mod from 1992 to 1993 in

Beijing Yuyan Xueyuan] xuexi Hanyu.

Beijing Language Institute study Chinese

(59) a. *[CP Hen darao Lisi de] [CP Zhangsan hai mei-you lai]. very bothers Lisi Mod Zhangsan yet not-have arrive

b. Zhangsan hai mei-you lai. Zhege hen darao Lisi. Zhangsan yet not-have arrive this very bothers Lisi 'Zhangsan hasn't arrived yet. This bothers Lisi a lot.'

To conclude, the examples above represent evidence that Chinese relative clauses modifying proper names are integrated appositives.

\subsection{Structure and derivation of non-integrated and integrated appositives}

The question that the Chinese data poses is the following: why can't its relative clauses, while being able to modify proper names and pronouns, and hence by virtue of this being able to have an appositive interpretation and qualify as integrated appositives, nevertheless be non-integrated appositives? 
The solution I propose is that in order to be non-integrated, an appositive relative clause needs to contain a specific type of relative pronoun, i.e., following Cinque (1982), a relative pronoun that is intrinsically referential. By being referential, such a pronoun can be interpreted as E-type. The proposal that the relative pronoun inside the appositive relative clause should be interpreted as an E-type one is not new (see Sells 1985 a, b; Demirdache 1991; Del Gobbo 2003). Taken seriously, it implies that the denotation of the appositive relative clause containing such E-type pronoun shouldn't be a predicate (as assumed, for example, by Potts 2005) but instead a proposition. All the differences between restrictives and integrated appositives on one side and non-integrated appositives on the other side follow from this (see Cinque 2008a; Del Gobbo 2007). More specifically, if the appositive relative clause is a proposition, it follows that it can be illocutionary independent. If the relative pronoun is E-type, hence referential, it follows that any syntactic category can function as its antecedent (see Sells 1985 a,b; Demirdache 1991 on this, among others) and that it can take split antecedents (see Ross and Perlmutter 1970; Moltmann 1992). ${ }^{14}$

In the same spirit of Cinque's (2008a) idea of Discourse Grammar, I thereby adopt Del Gobbo's (2007) proposal. At narrow syntax and at PF, we have the following structure: ${ }^{15}$

\footnotetext{
${ }^{14}$ As we have seen, Ross and Perlmutter (1970) first observed that some relative clauses can have split antecedents, as in the following example:
}

(i) A man entered the room and a woman went out who were quite similar.

(Ross and Perlmutter 1970)

Notice that, although not explicitly addressed in the literature, this type of relative clause cannot be introduced by a complementizer:

(ii) *A man entered the room and a woman went out that were quite similar.

The relative pronoun can refer to a split antecedent just like a referential pronoun can:

(iii) A man entered the room and a woman went out. They were quite similar.

This, for reasons that as far as I know are still unclear, is not possible if, instead of a relative pronoun, the relative clause is headed by an Operator or, in the terms established here, by a nominal deleted at PF because identical to the head of the relative.

${ }^{15}$ Notice that there is a crucial difference between the structure I propose for both integrated and nonintegrated appositives and the one that Cinque (2008a) proposes, as has been noted by one of the reviewer. Cinque, as spelled out in section 3.1, proposes that in integrated appositives, the IP is merged in a specifier of a nominal projection dominating DP; i.e., outside the scope of the determiner. When the external head $\mathrm{DP}_{1}$ moves, it lands to the specifier position of $\mathrm{CP}_{3}$ (see example (24) in the text). In the structure that I propose instead, both for the narrow syntax of the non-integrated appositives as well as for the entire derivation-up to $\mathrm{LF}$ - the entire $\mathrm{CP}_{3}$ is the complement of a head D. Such a determiner may remain silent or it may host a spelled-out determiner (usually an article). In the event it is silent, following Longobardi (1994), I claim that the proper name raises to that position, although I do not further investigate the issue in this paper. Notice that in Chinese, the D position may host a demonstrative. I propose such a modification to the structure put forth by Cinque because of the external visibility of the CP. In other words, nominals need to be some type of DP, hence the necessity of the additional DP layer. 
(60)

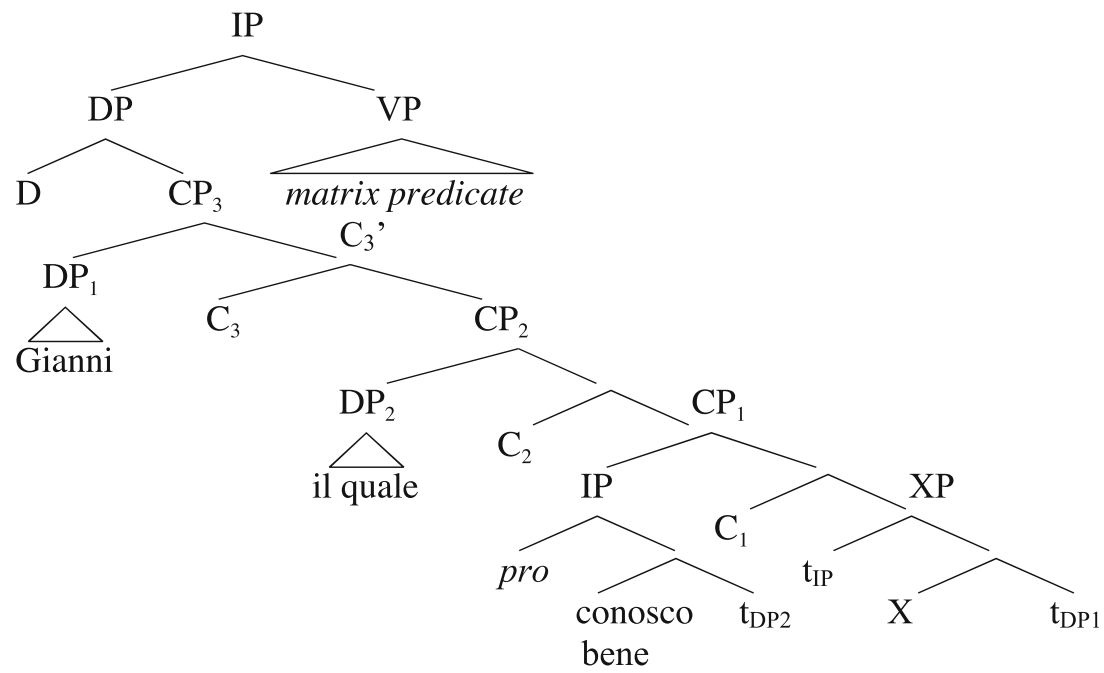

At LF and in Discourse Structure, $\mathrm{CP}_{2}$ detaches and merges to the right of the matrix sentence:

(61)

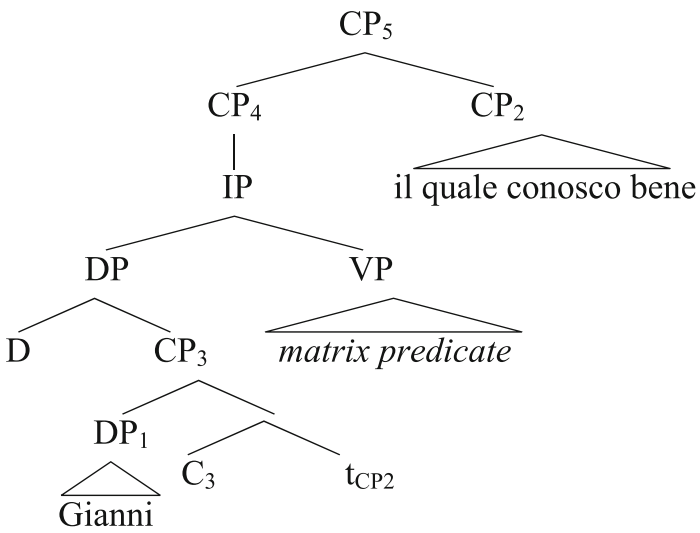

With this derivation, the E-type pronoun il quale can correctly pick up its reference from the preceding discourse, and we capture the fact that non-integrated appositives have the behavior of independent sentences, not simply predicates (see Del Gobbo 2007 for details on the E-type anaphora resolution).

In the case of integrated appositives, there is no detachment at LF and at discourse structure, and no E-type pronoun is present. Of this type of integrated appositive, we saw two instantiations, one in Italian and one in Chinese. Their respective structures are given below: 
(62)

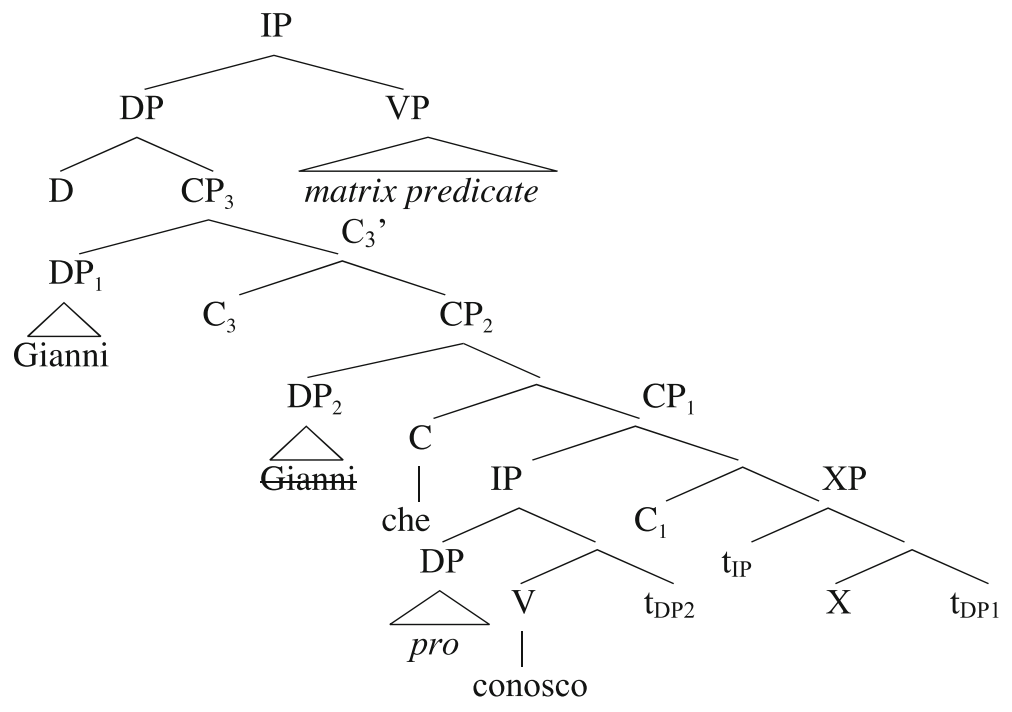

(63)

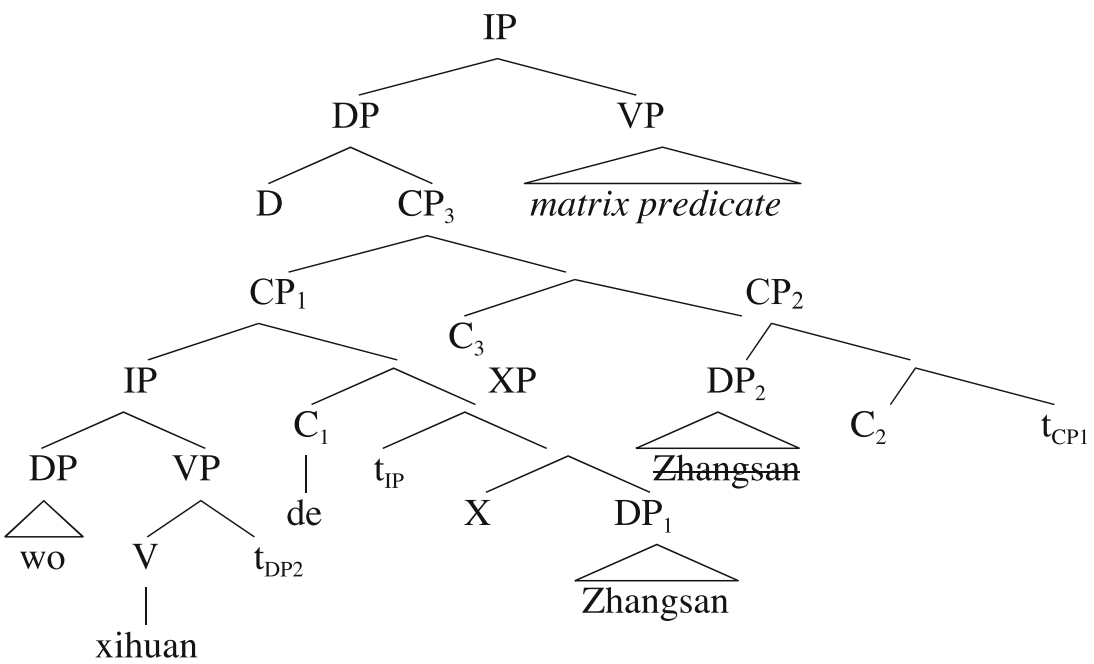

The most important difference between the structure in (61) and the two structures in (62)-(63) is the raising of the relative clause in (61) at LF and in discourse structure and the absence of such a movement in (62) and (63). This means that the relative clauses in the structures in (62) and (63) are always in the scope of elements higher up in the structure and of elements in the matrix, thereby accounting for the binding facts (parasitic gaps, binding of pronouns and anaphors (Safir 1986, Giorgi 1984, Cinque 2006a: fn. 9)).

Italian has both options: integrated appositive relative clauses and non-integrated ones. Only in the non-integrated ones, the pronoun is E-type, giving rise to the typical characteristics of canonical appositive relative clauses. Chinese, given the 
impossibility of it licensing a relative pronoun, can only allow an integrated appositive relative clause. This is why its appositive relatives don't share any of the canonical properties traditionally ascribed to appositive relative clauses.

\section{Deriving the typological differences}

I propose that non-integrated appositive relative clauses are the canonical ones: they are non-integrated, because they are parentheticals, so, at a certain level, they are independent sentences, hence propositions. All the properties we are aware of follow from this (see Cinque 2008a and Del Gobbo 2007 for details).

What do these canonical appositives need in order to be such? I propose that they require the following three conditions to be met:

1. The link needs to be spelled out, i.e., the relative pronoun needs to be overt (see Zhang 2001; Cinque 2006a, 2008a; Kayne 1994); it can't be an operator (so, in our terms, it can't be a raised nominal like the $\mathrm{dP}_{2}$ expensive book in (3) or the $\mathrm{dP}_{2}$ xiaohuozi in the Chinese matching structure in (7));

2. The appositive relative pronoun needs to be of the type that can also be used either in interrogatives or as a demonstrative (as claimed by Cinque 1982) ${ }^{16}$;

3. The relative pronoun needs to be interpreted as E-type. ${ }^{17}$

If one (or more) of the above conditions isn't met, the language resorts to the integrated appositive strategy. For example, Italian has the canonical appositive strategy, but given that it also has pronouns that cannot be used as E-type, it makes use of the integrated-type structure in these cases. Chinese doesn't satisfy any of the conditions above, as the relative pronoun is never overt, and it is never of the type used in interrogatives; therefore, for its appositives, Chinese is forced to use the integrated strategy.

16 In Italian, Cinque (1982) notices that the sentence in (i) is an integrated appositive, while the sentence in (ii) is a non-integrated one:

(i) Giorgio, a cui tieni, ti odia.

Giorgio to whom (you) care you $(\mathrm{Cl})$ hates

'Giorgio, who you care about, hates you.'

(ii) Giorgio, al quale tieni, ti odia.

Giorgio to whom (you) care you $(\mathrm{Cl})$ hates

'Giorgio, who you care about, hates you.'

The main difference is in the relative pronoun used. The relative form cui is not referential; it cannot for example occur as a wh-pronoun in questions, while this is the case for the relative proform il quale. Cinque (1982), following a suggestion by van Riemsdijk, proposes the following generalization: the pronoun in non-integrated appositives (using the most recent terminology) is one that does have nonanaphoric usages elsewhere in the language. This then includes both interrogative pronouns and demonstratives.

17 As cross-linguistically prenominal relative clauses do not seem to have overt relative pronouns, the linear order requirement Del Gobbo $(2003,2005)$ assumed-i.e., that in order to be truly appositive, a relative needs to follow its antecedent—can simply be reduced to the condition in 1 . 


\section{Conclusion}

Chinese appositive relative clauses are adjectival in the sense that they are integrated. Non-integrated appositives, i.e., the canonical appositive relative clauses, are an instantiation of E-type anaphora. Crucially, in order for a relative clause to be both syntactically and semantically a canonical appositive relative, it needs to contain a specific type of relative pronoun, overtly spelled out and interpreted as E-type. If we adopt Cinque's (2003, 2006a, 2008a) theory of relativization, for prenominal relatives we need to assume a structure and derivation that doesn't allow $\mathrm{dP}_{2}$ to be c-commanded by the head of the relative. It is this lack of c-command, I propose, that explains the unavailability of spelled-out relative pronouns in prenominal relative clauses. The nonexistence of relative pronouns in turn makes it impossible for Chinese relative clauses to be non-integrated appositives. The proposed theory leads us to make the following crosslinguistic empirical prediction: no prenominal relative clause can be appositive in the canonical sense, because no E-type pronoun can be licensed in its structure.

Acknowledgements For their comments and suggestions, I would like to thank Joseph Bayer, Anna Cardinaletti, Candice Cheung, Gennaro Chierchia, Guglielmo Cinque, Alexandra Cornilescu, Marcel den Dikken, Giuliana Giusti, Alex Grosu, Jim Huang and Audrey Li. My deepest thanks go to my consultants Grace Kuo, Ressy Ai, and Victor Junnan Pan. I am also thankful to two anonymous reviewers for providing insightful criticism, which led to significant improvement of the paper. All errors remain my sole responsibility. The research leading to this paper has been presented at the following venues: IsCLL11, National Chiao Tung University, Hsinchu, Taiwan; National Taiwan Normal University and Fu Jen University, Taipei; CUNY Syntax Supper Talks, Graduate Center, CUNY, New York; the Annual Conference of the English Department, University of Bucharest, Romania; 15th IACL/19th NACCL Joint Conference, Columbia University, New York; and the Linguistics Department Research Seminar, Ca' Foscari University, Venice, Italy.

Open Access This article is distributed under the terms of the Creative Commons Attribution Noncommercial License which permits any noncommercial use, distribution, and reproduction in any medium, provided the original author(s) and source are credited.

\section{References}

Aboh, O. Enoch. 2005. Deriving relative and factive clauses. In Contributions to the Thirtieth "Incontro di Grammatica Generativa”, ed. Laura Brugè, Giuliana Giusti, Nicola Munaro, Walter Schweikert, and Giuseppina Turano, 265-285. Venezia: Libreria Editrice Cafoscarina.

Abney, Steven. 1987. The English noun phrase in its sentential aspect. PhD diss., MIT.

Åfarli, Tor. 1994. A promotion analysis of restrictive relative clauses. The Linguistic Review 11, 81-100.

Aoun, Joseph, and Y. H. Audrey Li. 2003. Essays on the representational and derivational nature of grammar: The diversity of wh-constructions. Cambridge, MA: MIT Press.

Benincà, Paola, and Cecilia Poletto. 2004. Topic, Focus and V2: Defining the CP sublayers. In The structure of CP and IP, ed. Luigi Rizzi, 52-75. Oxford: Oxford University Press.

Cheng, Lisa. 1986. De in Mandarin. Canadian Journal of Linguistics 31: 313-399.

Cheng, Lisa. 1997. Marking modification in Cantonese and Mandarin. Ms., University of California, Irvine and HIL, Leiden.

Cinque, Guglielmo. 1982. On the theory of relative clauses and markedness. The Linguistic Review 1: 247-294.

Cinque, Guglielmo. 1988. La frase relativa. In Grande grammatica italiana di consultazione, vol. 1, ed. Lorenzo Renzi, 443-503. Bologna: Il Mulino. 
Cinque, Guglielmo. 2002. Complement and adverbial PPs: Implications for clause structure. Paper presented at the 25th Annual GLOW Colloquium, Amsterdam, April 9-11, 2002 (later published in Cinque 2006b, pp. 145-166).

Cinque, Guglielmo. 2003. The prenominal origin of relative clauses. Paper presented at the Workshop on Antisymmetry and Remnant Movement, NYU, New York.

Cinque, Guglielmo. 2005a. Deriving Greenberg's Universal 20 and its exceptions. Linguistic Inquiry 36: $315-332$.

Cinque, Guglielmo. 2005b. A note on verb/object order and head/relative clause order. In Grammar and beyond: Essays in honour of Lars Hellan, ed. Mila Vulchanova, and Tor A. Åfarli, 69-89. Oslo: Novus Press.

Cinque, Gugliemo. 2006a. Two types of appositives. University of Venice Working Papers in Linguistics $16,7-56$.

Cinque, Guglielmo. 2006b. Restructuring and functional heads. The Cartography of Syntactic Structures 4, ed. Guglielmo Cinque. Oxford: Oxford University Press.

Cinque, Guglielmo. 2008a. Two types of nonrestrictive relatives. In Empirical issues in syntax and semantics 7, ed. Olivier Bonami and Patricia Cabredo Hofherr, 99-137. Accessed 14 January 2009. http://www.cssp.cnrs.fr/eiss7.

Cinque, Guglielmo. 2008b. More on the indefinite character of the head of restrictive relatives. Rivista di Grammatica Generativa 33: 3-24.

Cinque, Guglielmo. In prep. The prenominal origin of relative clauses.

Citko, Barbara. 2008. An argument against assimilating appositive relatives to coordinate structures. Linguistic Inquiry 39: 633-655.

Del Gobbo, Francesca. 2001. Appositives schmappositives in Chinese. In UCI Working Papers in Linguistics 7, ed. Maki Irie, and Hajime Ono, 1-25. University of California, Irvine.

Del Gobbo, Francesca. 2002. Appositives and Chinese relative clauses. In CLS 38: The main session. Papers from the 38th Meeting of the Chicago Linguistic Society, vol. 1, ed. Mary Andronis, Erin Debenport, Anne Pycha, and Keiko Yoshimura, 175-190. Chicago: Chicago Linguistic Society.

Del Gobbo, Francesca. 2003. Appositives at the interface. PhD diss., University of California, Irvine.

Del Gobbo, Francesca. 2004. On prenominal relative clauses and appositive adjectives. In WCCFL 23 Proceedings, ed. B. Schmeiser, Vineeta Chand, Ann Kelleher, and Angelo Rodriguez, 182-194. Somerville, MA: Cascadilla Press.

Del Gobbo, Francesca. 2005. Chinese relative clauses: Restrictive, descriptive or appositive? In Contributions to the XXX Incontro di Grammatica Generativa, ed. Laura Brugè, Giuliana Giusti, Nicola Munaro, Walter Schweikert, and Giuseppina Turano, 287-305. Venezia: Cafoscarina.

Del Gobbo, Francesca. 2007. On the syntax and semantics of appositive relative clauses. In Parentheticals, ed. Nicole Dehè and Yordanka Kavalova, 173-201. Amsterdam: John Benjamins.

Del Gobbo, Francesca. 2008-2009. More appositives in heaven and earth than are dreamt of in your linguistics. Paper presented at the 83rd Annual Meeting of the LSA, San Francisco, and at WECOL, UC Davis.

Del Gobbo, Francesca. In prep. More appositives in heaven and earth than are dreamt of in your linguistics. Ms., University of California, Irvine.

Demirdache, Hamida. 1991. Resumptive chains in restrictive relatives, appositives and dislocation structures. PhD diss., MIT.

Dikken, Marcel Den. 2006. Relators and linkers: The syntax of predication, predicate inversion, and copulas. Cambridge, MA: MIT Press.

Dikken, Marcel Den, and Pornsiri Singhapreecha. 2004. Complex noun phrases and linkers. Syntax 7: $1-54$.

Downing, Bruce T. 1978. Some universals of relative clause structure. In Universals of human language, vol. 4: Syntax, ed. Joseph H. Greenberg, 375-418. Stanford: Stanford University Press.

Engdahl, Elisabet. 1983. Parasitic gaps. Linguistics and Philosophy 6: 5-34.

Fukui, Naoki, and Yuji Takano. 2000. Nominal structure: An extenstion of the symmetry principle. In The derivation of vo and ov, ed. Peter Svenonius, 321-362. Dordrecht: Kluwer.

Gärtner, Hans-Martin. 2001. Are there V2 relative clauses in German? The Journal of Comparative Germanic Linguistics 3, 97-141.

Giorgi, Alessandra. 1984. Towards a theory of long-distance anaphors: A GB Approach. The Linguistic Review 3: 307-361.

Huang, C.-T. James. 1982. Logical relations in Chinese and the theory of grammar. PhD diss., MIT.

Huang, C.-T. James, Audrey Y.-H. Li, and Yafei Li. 2009. The syntax of Chinese. Cambridge: Cambridge University Press. 
Kayne, Richard S. 1994. The antisymmetry of syntax. Cambridge, MA: MIT Press.

Kayne, Richard S. 1999. Prepositional complementizers as attractors. Probus 11: 39-73.

Kayne, Richard S. 2000. A note on prepositions, complementizers, and word order universals. In Parameters and universals, 314-326. New York: Oxford University Press.

Kayne, Richard S. 2002. On some prepositions that look DP-internal: English of and French de. Catalan Journal of Linguistics 1: 71-115.

Keenan, Edward L. 1985. Relative clauses. In Language typology and syntactic description, vol. II: Complex Constructions, ed. Timothy Shopen, 141-170. Cambridge: Cambridge University Press.

Koster, Jan. 2000. Extraposition as parallel construal. Ms., University of Groningen.

Lai, Janet. 2008. Complete Mandarin Chinese: The basics. New York: Living Language, Random House.

Larson, Richard K., and Naoko Takahashi. 2007. Order and interpretation in prenominal relative clauses. In MIT Working Papers in Linguistics 54: Proceedings of the Workshop on Altaic Formal Linguistics II, ed. Meltem Kelepir and Belkiz Öztürk, 101-120. Cambridge, MA: MITWPL.

Lin, Jo-wang. 2003. On restrictive and non-restrictive relative clauses in Mandarin Chinese. Tsinghua Journal of Chinese Studies, New Series, 33: 199-240.

Longobardi, Giuseppe. 1994. Reference and proper names. Linguistic Inquiry, 25: 609-666.

Moltmann, Friederike. 1992. Coordination and comparatives. PhD diss., MIT.

Paul, Waltraud. 2006. The insubordinate subordinator de in Mandarin Chinese, ms., CNRS, CRLAO, EHESS, Paris.

Potts, Christopher. 2005. The logic of conventional implicatures. Oxford: Oxford University Press.

Reinhart, Tanya 2006. Interface strategies: Optimal and costly computations. Cambridge, MA: MIT Press.

Rizzi, Luigi. 1997. The fine structure of the left periphery. In Elements of grammar: Handbook of generative syntax, ed. Liliane Haegeman, 281-337. Dordrecht: Kluwer.

Ross, John R., and David Perlmutter. 1970. Relative clauses with split antecedents. Linguistic Inquiry 1: 350 .

Safir, Ken. 1986. Relative clauses in a theory of binding and levels. Linguistic Inquiry 17: 663-689.

Sauerland, Uli. 1998. The meaning of chains. PhD diss., MIT.

Sauerland, Uli. 2000. Two structures for English restrictive relative clauses. In Proceedings of the Nanzan Glow, ed. Yasuaki Abe, Hiroshi Aoyagi, Masatake Arimoto, Keiko Murasugi, Mamoru Saito, and Tatsuyo Suzuki. 351-366. Nagoya: Nanzan University.

Sauerland, Uli. 2003. Unpronounced heads in relative clauses. In The interfaces: Deriving and interpreting omitted structures, ed. Kerstin Schwabe and Susanne Winkler, 205-226. Amsterdam: Benjamins.

Sells, Peter. 1985a. Anaphora and the nature of semantic representation. Ms., Stanford: CSLI.

Sells, Peter. 1985b. Restrictive and non-restrictive modification. CSLI Report No. 85-28. Stanford: CSLI Publications.

Sheehan, Michelle. 2010. The resuscitation of CED. To appear in The Proceedings of NELS 2010. Amherst, MA: GLSA, University of Massachusetts, Amherst.

Tsao, Feng-fu 1986. Relativization in Chinese and English: A contrastive study of form and function. Journal of Chinese Language Teachers Association 21: 13-47.

Vries, Mark de. 2002. The syntax of relativization. Doctoral dissertation, Netherlands Graduate School of Linguistics.

Vries, Mark de. 2006. The syntax of appositive relativization: On specifying coordination, false free relatives, and promotion. Linguistic Inquiry 37: 229-270.

Vries, Mark de. 2007. Invisible constituents? Parentheticals as b-merged adverbial phrases. In Parentheticals, ed. by Nicole Dehé and Yordanka Kavalova, 203-234. Amsterdam: John Benjamins.

Williams, Edwin. 1977. Discourse and logical form. Linguistic Inquiry 8: 101-139.

Zhang, Niina. 2001. On the absence of nonrestrictive relatives in Chinese. Ms., ZAS, Berlin.

Zhang, Niina. 2007. The syntactic derivations of split antecedent relative clause constructions. Taiwan Journal of Linguistics 5: 19-47. 